\title{
1 Multiple-text Manuscripts
}

Manuscripts come in many forms. This is especially true for a vast collection the size of the Dunhuang corpus, which contains tens of thousands of items written over the course of several centuries, in a variety of languages. In addition to the one-text-per-one-manuscript model, there are also many physically homogeneous manuscripts which include discrete texts written in succession, sometimes in the same hand, but not necessarily so. Among the Dunhuang manuscripts, a particular group of such multiple-text manuscripts stand out. ${ }^{49}$ These are about three dozen codices or concertinas with several shorter Buddhist scriptures, incantations, or mantras. As a group, they have obvious typological similarities, yet the selection of texts and their order is almost never the same, suggesting they were intended for personal use and it was the individual owner determining which texts to include and in what order.

Former researchers have drawn attention to such manuscripts, recognising them as a distinct group. Makita Tairyō 牧田諦亮 described them as 'scriptures written in succession' (renshakyo 連寫經), referring to the fact that the same manuscript contained multiple consecutive texts. ${ }^{50}$ Later he used the same expression for the whole group and noted that many of the texts were apocryphal scriptures, some of which-for historical reasons-survived only in Dunhuang. ${ }^{51}$ Hypothesising about the function of such booklets, Stephen F. Teiser raised the possibility that they may have been temple copies used by monks in practical services. ${ }^{52}$ Kuo Liying discussed these manuscripts in the context of apocryphal texts, highlighting their connection with esoteric practices. ${ }^{53}$ In his study of the history of Chinese bookbinding, Li Zhizhong 李致忠 drew attention to the physical peculiarities of such manuscripts, calling them 'compendium' booklets, which is a codicological term analogous with the concept of multiple-text manuscript

49 In using 'multiple-text manuscript' as a technical term, I follow Bausi, Friedrich and Maniaci 2019, the contributions in which examine the phenomenon across different manuscript cultures. 50 Makita 1964, 366 and Makita 1976, 38-39. Tanaka Ryōshō 田中良昭 (1967, 104) used the same expression in connection with the same manuscripts.

51 In Tanaka and Makita's usage, renshakyō was not really a term but a descriptive expression for such manuscripts. This is why taking it as a technical term and translating it as "chain scriptures' (Schmid 2011; 268, Wang 2018, 1999), 'chain sutras' (Mollier 2008, 16), or 'linked sutras' (Goodman's 2013, 38) is not ideal.

52 Teiser 1994, 99-100.

53 Kuo 2000, 694-695; see also Schmid 2011, 368-369. 
used in this chapter. ${ }^{54}$ Amanda Goodman emphasised how the analysis of the physical format had the potential to reveal a great deal about how the constituent texts were understood at the time..$^{55}$

This chapter examines multiple-text manuscripts in a holistic way, including both content and form, hoping to gain insights into their production and use. My initial approach, therefore, is from the point of view of the typology of book form and binding, contrasting these features with those in other manuscripts. While textual content is an equally important part of the equation, I hope to go beyond the practice of focusing solely on the texts. ${ }^{56}$

As we will see below, such manuscripts may have been produced collectively by smaller groups of individuals as acts of religious offering. The personal transcription of a text would have triggered the religious efficacy of the manuscript and appropriated the merit generated by the copying. As most similar items are small booklets, it is not unreasonable to assume they were carried on the body and possibly served an apotropaic function. Conversely, the fact that such multiple-text manuscripts make up a substantial portion of the total number of surviving codices and concertinas is an indication that the religious motivation involved in their production also played a role in the spread of these book forms in Dunhuang and elsewhere.

\subsection{New book forms in Dunhuang}

The ninth century saw the appearance of several new book forms in Dunhuang. Although in terms of overall numbers the scroll remained the dominant form, the introduction of folded and layered manuscripts was a milestone in the history of the Chinese book. This was the time when Chinese books first began having pages and, consequently, folio numbers. ${ }^{57}$ Due to only a small portion of the relevant items being dated, it is hard to pinpoint the exact moment when such book forms made their debut. Most researchers date them to the Tibetan and the Guiyijun periods, when the region's closest ties were not with the Tang empire

54 Li 1989, 115. Naturally, the term is the choice of word on the part of the translator (Frances Wood) who translated the original article into English.

55 Goodman 2013, 38-39.

56 In my approach, I am following the example of earlier scholars such as Fujieda Akira, Stephen F. Teiser and Jean-Pierre Drège, all of whom have been successful in merging these two aspects in their study of Dunhuang manuscripts.

57 Although still relatively rare in Dunhuang, folio numbers later became an important device in printed books. On the significance of the page format, see Mak 2014. 
and its successor states but with Central Asia and Tibet, resulting in new types of cultural stimuli.

The new book forms differ from the dominant scroll in marked ways. Fujieda Akira dubbed them 'irregular formats' as a means for distinguishing them from the 'standard format' of the scroll. ${ }^{58}$ Naturally, the terms 'irregular' and 'standard', with their normative connotations, are not ideal as conceptual categories. It is true, however, that the new forms deviate from the majority of Chinese manuscripts, even if this is by no means the case for Tibetan ones. They are also less uniform than scrolls which often followed prescribed standards and thus tended to be of similar size and layout. In contrast, the new forms exhibit considerable diversity in size and shape. From the point of view of general physical structure, we can identify three major types: 1) the pothi, 2) the concertina and 3) the codex. Unlike the scroll, which is a longer stretch of paper rolled up around a central axis, all three new forms consist of folia stacked or folded into a single booklet. In the following, I briefly examine the main characteristics of these three types. ${ }^{59}$

\subsubsection{Pothi}

The pothi book consists of oblong rectangular folia stacked together. The prototype of this form is the Indian palm-leaf manuscript (Skt. pustaka > pothi) which is still in use in parts of South and South-East Asia. Pothis from Dunhuang and other sites in Western China structurally replicate the same palm-leaf manuscripts but using paper. The switch to paper may have been related to the limited availability of palm leaves in the desert climate of Chinese Central Asia, although the popularity of paper in the region must have also been a decisive factor. Accordingly, the pothi folia made of paper retain the shape of palm leaves, including the string holes originally used to bind the leaves together. This remains so in Dunhuang, although the holes usually do not serve a practical function and at times are merely drawn on the surface, leaving the paper unperforated. Evidently, the holes remained part of the design symbolising a

58 Fujieda 1966, 16-27.

59 For a brief overview of the history of research on the book forms in Dunhuang, see Drège 2018, 25-28. 
connection to earlier stages of the Buddhist manuscript tradition. ${ }^{60}$ They survived as a design feature, as a reference to an earlier stage of the Buddhist book. ${ }^{61}$

The majority of pothi books from Dunhuang are in Tibetan, and only relatively few are in Chinese. Although manuscripts in pothi form survive in various languages from other sites in Western China, their appearance in Dunhuang is unquestionably linked with the Tibetan presence. Accordingly, Jean-Pierre Drège dates the introduction of the pothi to the second half of the eighth century. ${ }^{62} \mathrm{Ti}$ betans wrote on the pothi leaves horizontally, with lines parallel to the long edge of the leaves, similar to the way scribes in India and Central Asia wrote on them with scripts that had a horizontal orientation. When writing Chinese, the leaves had to be turned 90 degrees for the vertical lines of text to remain parallel to the long side. This was a simple solution that presented no difficulties unless the languages were to be mixed.

An example of a Chinese pothi is manuscript S.5635, a single folio $26.6 \times 9.2 \mathrm{~cm}$ in size, with the beginning of the Weimojie suoshuo jing 維摩詰所說經 (Skt. Vimalakirti-nirdeśa-sūtra; Sutra Spoken by Vimalakīrti). Fig. 1 shows the recto and verso of the same folio side by side. The paper is not ruled, as was often the case with pothi manuscripts. Nevertheless, the beginning and end of the lines are aligned (i.e. justified), forming distinct top and bottom margins. Each page contains seven lines of text, each with $27-29$ characters. ${ }^{63}$ The string hole in the centre of the upper part of the folio is circled with red ink, which was common in pothis from Dunhuang. Although one of the corners of the folio seems to be damaged, the other three reveal that the corners used to be rounded. Rounded corners were also common in pothi manuscripts in other languages, most likely reflecting the legacy of palm-leaf manuscripts. ${ }^{64}$

60 In a letter to Émile Senart, Paul Pelliot $(1908,508)$ attributed the use of the pothi format for Chinese books to the religious piety of Chinese believers, which drove them to imitate the Indian pothi. For an English translation of this part of the letter, see Drège 2018, 20-21.

61 In a way, this is similar to how modern PDF and Word documents retain the page-based format of physical books (i.e. codices), including margins and headers, even though this is far from being the ideal format for computer screens with their landscape orientation.

62 Drège 2014d, 362; cf. Moretti forthcoming.

63 Other than the lines with titles, of course.

64 A related feature is that in some instances the opposing edges of the leaves are not parallel but slightly curved, so the leaves resemble a superellipse instead of a rectangle. This practice was not limited to Dunhuang but is also seen in manuscripts from the southern part of the Tarim Basin. See, for example, some of the pothi leaves Aurel Stein excavated in 1901 at Dandān-Uiliq and Endere along the southern perimeter of the Taklamakan Desert; Stein 1907, v. 2, Plates CVII-CX. 


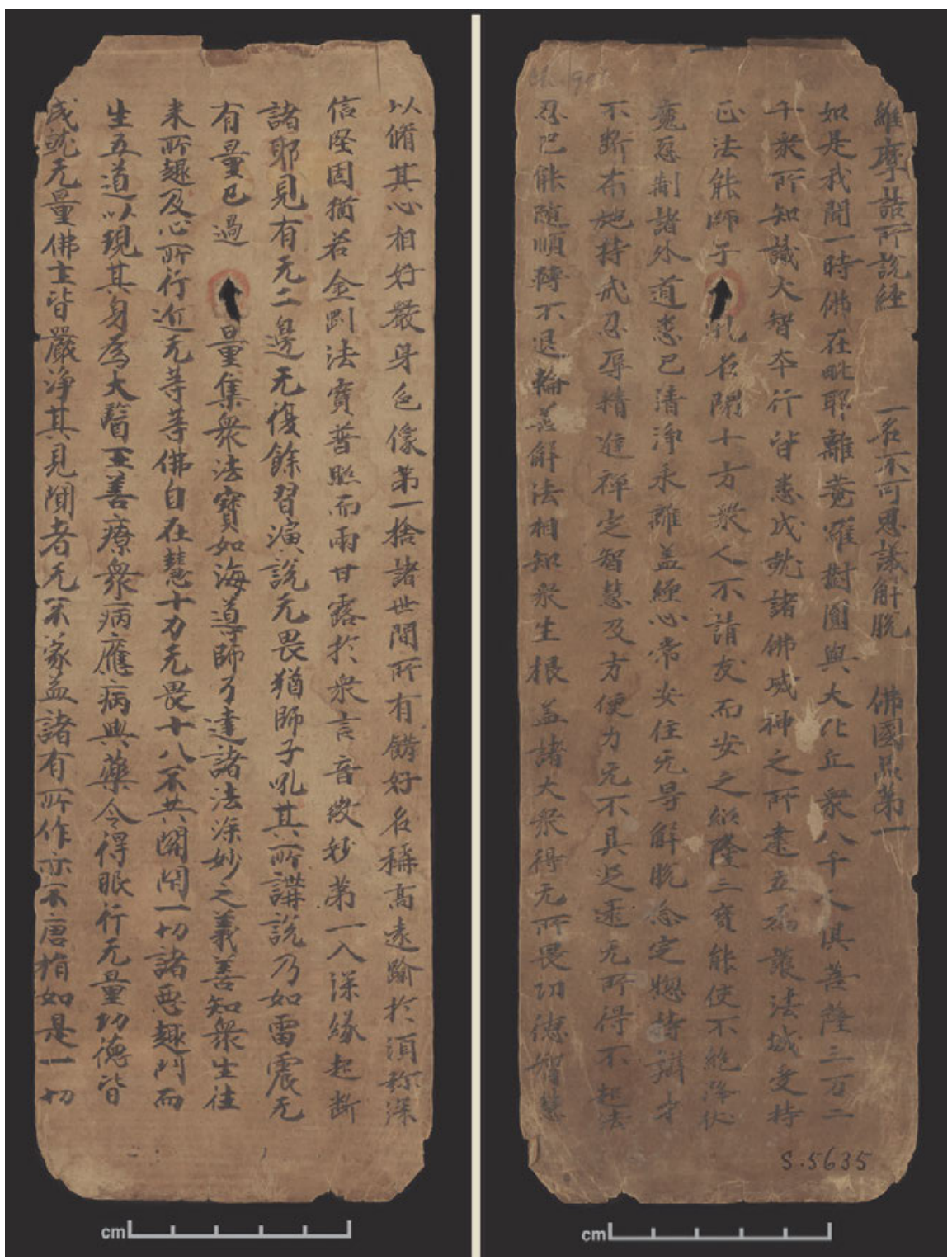

Fig. 1: The recto and verso of a pothi folio, manuscript S.5635. $(26.6 \times 9.2 \mathrm{~cm}$; The British Library) 


\subsubsection{Concertina}

The concertina is essentially a scroll folded at regular distances in alternating directions. The result is a book that can be unfolded by pulling it apart. This form is also known in English as 'accordion', 'leporello', 'pleated binding' or, using its Japanese name, orihon 折本 ('folded book'). ${ }^{65}$ The most common Chinese name is jingzhe zhuang 經摺裝, which is sometimes translated into English as 'sutra binding' or 'folding sutra binding' ${ }^{66}$ This form is known both in the West and in South-East Asia but the earliest surviving examples are those from Dunhuang. ${ }^{67}$

As a book form, the concertina is primarily attested in Dunhuang for Tibetan manuscripts, and this may also indicate its origin. Drège notes that only slightly more than $10 \%$ of the concertinas are in Chinese and considering that almost all of the few unambiguously dated specimens come from the second half of the tenth century, it is unlikely that this form would have been used before the Tibetan control of Dunhuang (i.e. 781). ${ }^{68}$ In view of the fact that there are over three hundred such manuscripts from Dunhuang and none of the dated ones predates the tenth century, the connection to the Tibetan period seems to rest primarily on the assumption that that was the moment when the Tibetan cultural influence was at its zenith in the region. Yet, as we know today, Tibetan culture remained a strong presence even after the end of Tibet's political rule. ${ }^{69}$ Judging solely from the dates in colophons, the Chinese concertinas are firmly within the time frame of the Guiyijun period.

As a general rule, the unambiguously dated examples are Chinese, as Tibetan manuscripts typically record the date using the twelve-year cycle, which does not tell us the precise year. In his study of a Tibetan multiple-text concertina manuscript known as the Tibetan Chan Compendium (P. Tib. 116), Sam van

65 The Japanese word orihon (also spelled ori-hon) was adopted into the English language by the second half of the nineteenth century at the latest; e.g. Audsley 1882, 85; cf. Evans 1997, 134. Discussing medical books bound in this form from late imperial China, Unschuld 2010 uses the term 'leporello'. In the context of manuscripts from South-East Asia, these books are often called 'folding books' or 'folded books'; see Terwiel and Chaichuen 2003.

66 E.g. Tsien 1985, 230 and Burkus-Chasson 2005.

67 For examples of fifteenth-century English manuscripts in this type of binding, see Shirota 2019. For an overview of this form in the Aethiopian manuscript tradition from the fifteenth century onward, see Balicka-Witakowska 2010; in pre-Islamic Java, see Jákl 2016.

68 Drège 2014a, 365. The numbers are based on manuscripts from the Stein and Pelliot collections.

69 Takeuchi 1990 and 2004; van Schaik and Galambos 2012, 67-68. 
Schaik notes that the handwriting points to the period from the mid-ninth century onwards, which is perfectly compatible with the dates in dated Chinese concertinas. ${ }^{70}$ Combining such palaeographic evidence with the tenth-century dates of Chinese concertinas, van Schaik tentatively dates the manuscript to the first half of the tenth century. Yet the question remains whether the concertina as a book form was in use in Dunhuang prior to the mid-ninth century when Tibet's political control ceased. If this had indeed been the case, the questions to be asked are why had it not become popular earlier, the moment the Tibetans had taken control of the region? And if this really was a new phenomenon in Tibetan manuscript culture, what triggered its development?

Although the concertina is in a sense an extension of the scroll form, the folded pages in Dunhuang are mostly tall and narrow, with folia resembling the shape of pothi leaves. In some cases, the panels include the string holes we see in pothi manuscripts. If anything, the purely symbolic function of such holes is even more obvious in concertinas than in pothi manuscripts. ${ }^{71}$ One such item, shown in Fig. 2, is the bilingual manuscript S.5603, in which the main text in black ink is a Chinese-language commentary to the Lañkāvatāra sūtra, whereas the text added in red between the lines is the Tibetan text of the sutra without the commentary. ${ }^{72}$ In its closed form, the stacked leaves resemble a codex, yet when fully spread out, it is in the shape of an unrolled scroll. At the same time, the individual folia are in the shape of pothi leaves and include the string hole. Thus, in terms of its shape and structure, this particular manuscript combines features of the three book forms (i.e. scroll, pothi and codex). In this example, both the Chinese and Tibetan texts run parallel to the long side of the page, which indicates that the book had to be oriented differently depending on which language was read.

70 van Schaik 2016, 293.

71 Paul Pelliot was the first to note the genetic relationship between pothis and concertinas; see Pelliot 1908, 509, Drège 2018, 21.

72 Ueyama 1990, 389-397. 


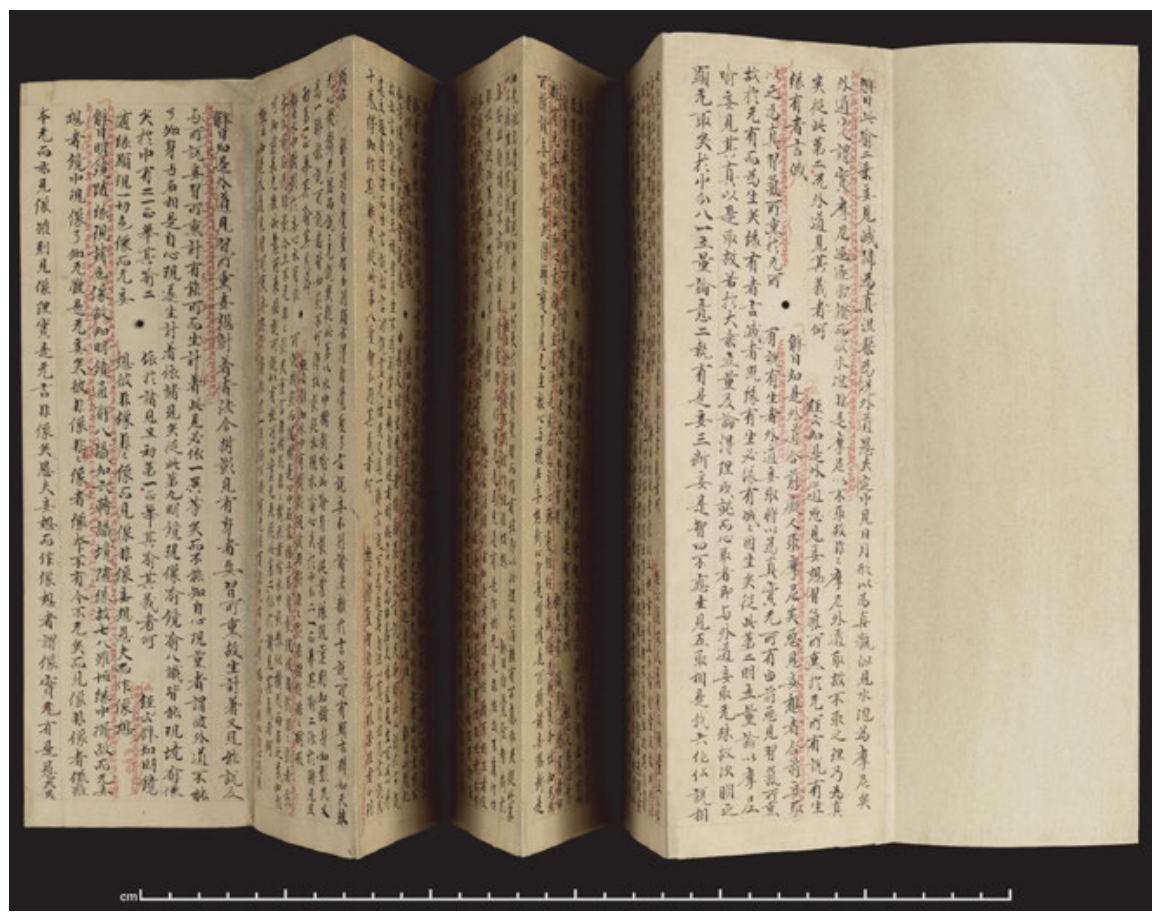

Fig. 2: Manuscript S.5603 in a concertina form. $(29.2 \times 9.1 \mathrm{~cm}$; The British Library $)$

Less commonly, the shape and dimensions of concertinas resembled those of codices. For example, manuscripts $S .5541(8.2 \times 7.2 \mathrm{~cm})$ and $S .5587(7.3 \times 5.4 \mathrm{~cm})$ have a less elongated shape reminiscent of codices. ${ }^{73} \mathrm{~A}$ fascinating example are the three printed copies of the 32-section version of the Diamond sutra from the mid-tenth century (Or.8210/P.11, P.4515 and P.4516), all folded as a concertina but with codexlike dimensions. Fig. 3 shows two opposing pages from item Or.8210/P.11, a printed copy commissioned in 949 by Cao Yuanzhong 曹元忠 (d. 974), the ruler of Dunhuang. After being printed, the paper sheets were assembled into a concertina, which in its current form only has sections Nos. 1, 2 and 32 of the text. That the

73 Two miniature concertinas with such non-pothi like proportions were discovered in a relic deposit dating from 1049 inside the White Pagoda in Balin Right Banner, Inner Mongolia. The smaller $(5.2 \times 3 \mathrm{~cm})$ contained the Foshuo Molizhitian jing 佛說摩利支天經 and the larger $(5.5 \times$ $4 \mathrm{~cm}$ ), the Diamond sutra; see De, Zhang and Han 1994, 23; also Shen 2006, 77-79. These booklets were evidently used as amulets and formed part of the Esoteric Buddhist practice of empowerment. 
omission of other sections was not the result of damage to the once complete book and that the current condition is in fact its original structure is implied by the two other copies, the content of which partially overlaps with this copy. ${ }^{74}$ The presence of a printed frame indicates that the page-based layout was part of the design from the start, and that the concertina is not a remounted scroll. In contrast to concertinas with pothi-shaped leaves, those with codex-shaped dimensions may have been intended to emphasise an affiliation with the codex, a form that was neither Chinese nor Tibetan.

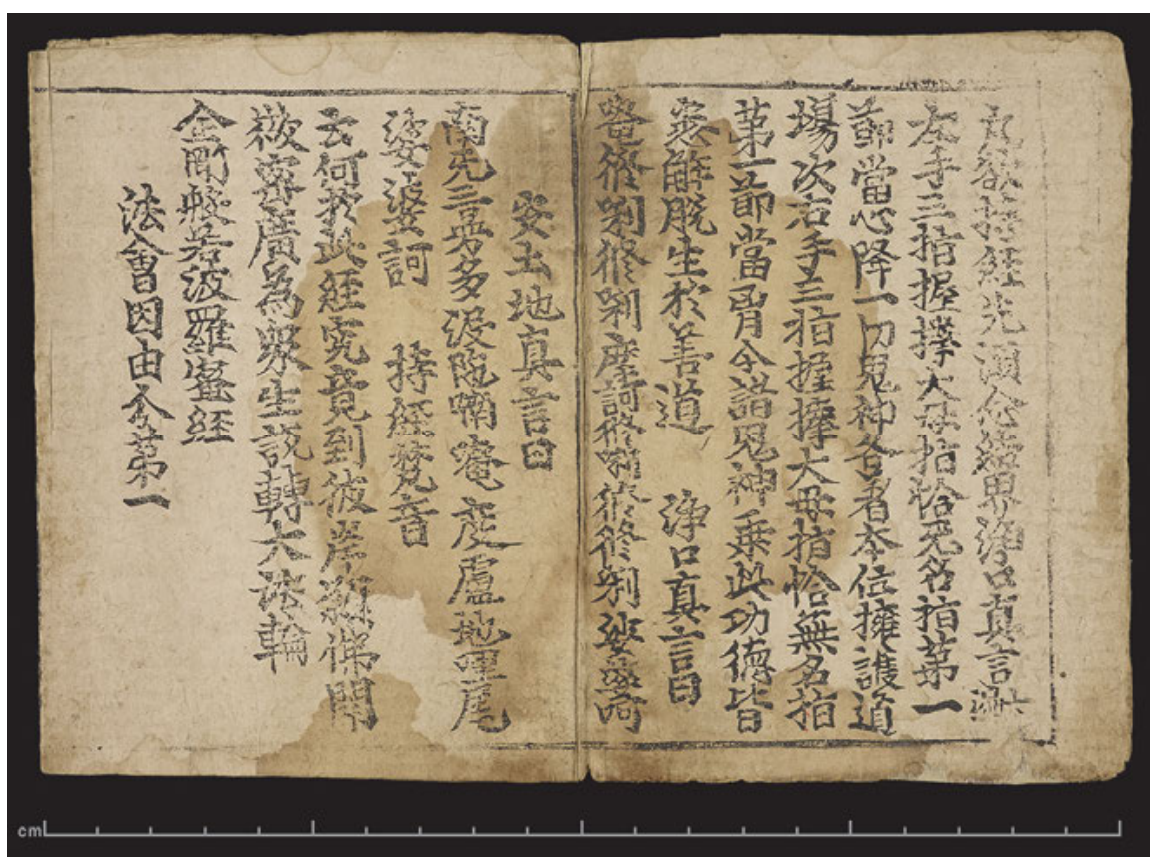

Fig. 3: A printed copy of the Diamond sutra in Or.8210/P.11. $(14 \times 10.2 \mathrm{~cm}$; The British Library). ${ }^{75}$

74 P.4515 contains sections No. 31 and 32, followed by a series of spells; P.4516 has sections No. 1 and 2.

75 The manuscript dimensions in the captions to figures refer to a single folio, which would be the size of the closed book, even when the figure displays, as it does in this case, more than one page. 


\subsubsection{Codices}

The codex is a book that consists of one or more quires or gatherings (also called signatures). The quires, in turn, comprise several bifolia stacked together and folded in half, then sewn together in the middle. Essentially, this is the same book form that spread throughout the Western world during the period of Late Antiquity and ultimately evolved into the modern book. ${ }^{76}$ Even the method of successively folding larger sheets of paper to create quires was identical to how vellum or parchment sheets were folded in the West. ${ }^{77}$ There is little doubt that the appearance of the codex in the Sinophone (or rather, Sinographic) world is indebted to contact with Western manuscript cultures, even if the exact trajectory of the borrowing remains unclear. ${ }^{78}$ According to Jean-Pierre Drège, there are about four hundred codices known from Dunhuang and twenty-six of these bear a date. The earliest date is 899 (P.3913) but some of the undated ones may be from even earlier. ${ }^{79}$

In general, the codex in Dunhuang has two major types. The first one is the sewn one, structurally identical to Western codices in that it consists of quires assembled into a book. The bifolia in each quire are sewn together along the centrefold, ensuring that the leaves do not come loose. A codex may have one or more quires, depending on its size. In the second type, the bifolia are similarly folded in half but instead of being gathered into quires, each folded bifolio is glued to the next one along the outer edge of the centrefold (Fig. 4). ${ }^{80}$ Despite this basic difference, the two types of codices are very similar in most other aspects. Unlike the so-called 'thread-bound books' (xianzhuang shu 線裝書) that became the norm in later centuries, in which only one side of the leaves held writing and the blank side was on the inside, in Dunhuang people usually wrote on both sides. ${ }^{81}$

76 The literature on the origin and development of the codex is too vast to enumerate here. Some important contributions include Turner 1977, Roberts and Skeat 1983, van Haelst 1989, Harris 1991, Harnett 2017 and Boudalis 2018. On non-European codices, see the relevant entries in the volume Comparative Oriental Manuscript Studies: An Introduction (Bausi et al. 2015).

77 On the folding of papers sheets into quires, see Drège 2014b.

78 Drège 2018, 28 opines that 'the spread of books carried by occidental religions, Nestorianism or Manichaeism, may have had an influence on the Chinese book'.

79 Drège 1979, 18 and Drège 2014b, 373.

80 This type of binding is often referred to as 'butterfly binding' 蝴蝶裝, although some scholars use the same term for other types of bindings. To avoid ambiguity and confusion, I do not use this term here. 81 This was not a universal rule and there are manuscripts in which some leaves have text on one side only, leaving the blank side exposed, or gluing it to the blank side of the adjacent folio. We can see both scenarios, for example, in manuscript P.3759, a small multiple-text codex merely $5.1 \times 4.7 \mathrm{~cm}$ in size. 


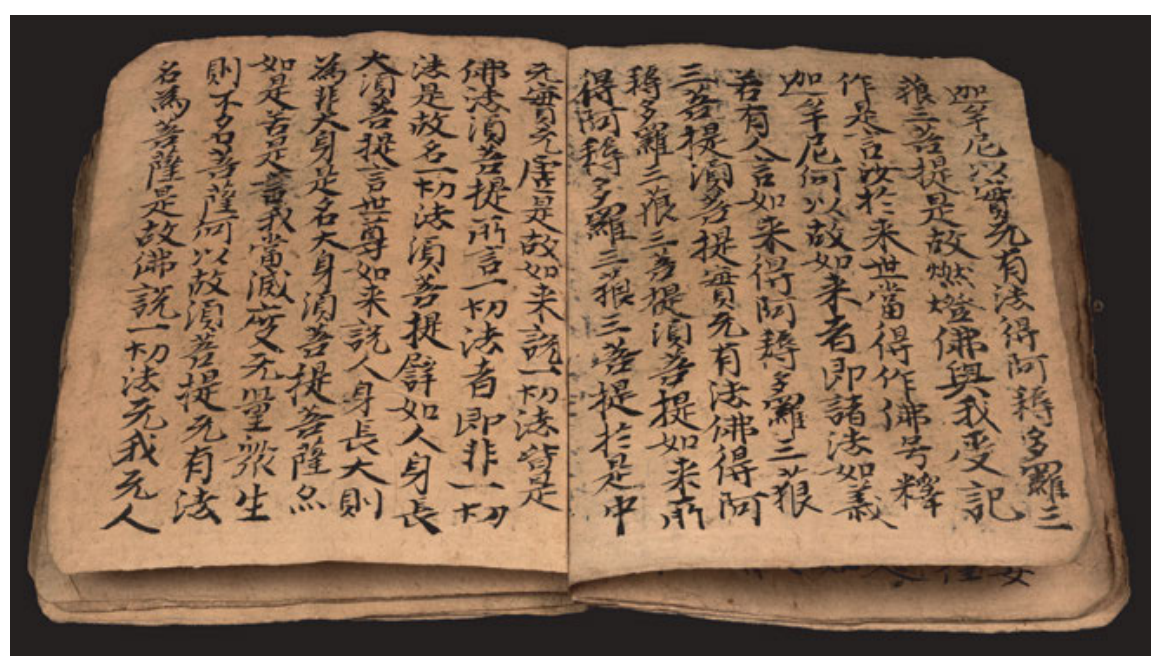

Fig. 4: Manuscript S.5451, an example of a glued codex. $(14 \times 11.2 \mathrm{~cm}$; The British Library $)$

Another major difference was, of course, that in Dunhuang codices the folds were at the spine, whereas in later Chinese books they were on the outside, forming the fore-edge of the book.

An often overlooked feature of Dunhuang codices is that many of them were folded in half vertically in parallel with the spine. Modern curators and conservators usually flatten them because they tend to see them as objects that essentially had the same structure as western books. Yet even after a century of modern curatorial care, many of them retain a little 'muscle memory' and curl upwards upon removal from their envelope or box. Evidently, such booklets were folded when they were carried. Fig. 5 shows the front cover of manuscript S.5638 $(13.6 \times 13.2 \mathrm{~cm})$, a small codex almost square in shape. At the centre, the trace of the vertical fold is visible, indicating how the manuscript used to be folded, even though the booklet is relatively small. ${ }^{82}$

82 A less likely scenario is that this occurred when the manuscripts were packed up for storage in the library cave. Some of the larger Tibetan pothi manuscripts, for instance, were rolled up, which was not the usual manner in which they were stored. 


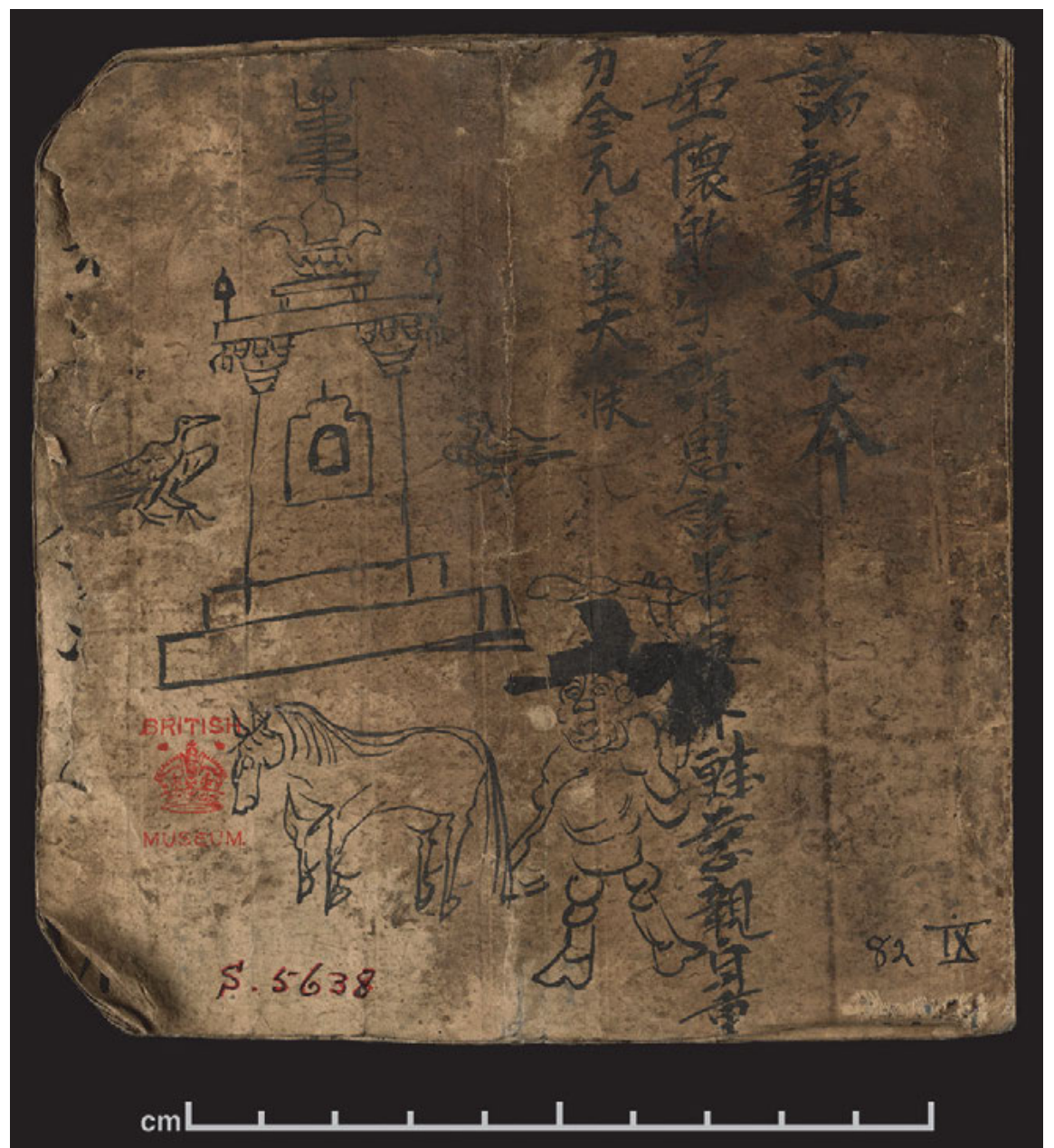

Fig. 5: The front cover of codex S.5638. $(13.6 \times 13.2 \mathrm{~cm}$; The British Library)

The small size of some codices inevitably raises the issue of portability. When viewing them purely as digital images, which is so often the case, it is easy to forget how small some of them are in reality. In contradistinction to many other manuscript traditions, the Dunhuang codices are never large. Neither are there any lavishly illuminated exemplars, as it was the case in Manichaean book cul- 
ture. ${ }^{83}$ Some items contain drawings or paintings but, on the whole, these are relatively simple. The manuscripts themselves are also unsophisticated, suggesting personal, rather than public use. ${ }^{84}$

Another physical trait, possibly related to portability, is that most codices had trimmed corners. It is easy to see that this would have protected the corners from damage, ${ }^{85}$ especially as the Dunhuang codices usually had no hard binding. Yet this feature was probably not a local invention but arrived at Dunhuang along with the codex form itself. Trimmed corners occur in a disproportionally high number of codices, exhibiting two main variations: rounded and bevelled (i.e. cut along a straight line at 45 degree angle) ones. The division between the two is not always obvious, showing that they represented more of a sliding scale, rather than two opposite poles. Fig. 6 shows manuscript S.5442, a small glued codex $(10 \times 10.8 \mathrm{~cm})$ with bevelled corners. The pattern of the corners repeats on all bifolia and the irregular traces of the blade demonstrate that the bifolia were trimmed together, while the book was closed. Whatever their original function, trimmed corners were clearly part of the basic design of Dunhuang codices, a feature present in most of them.

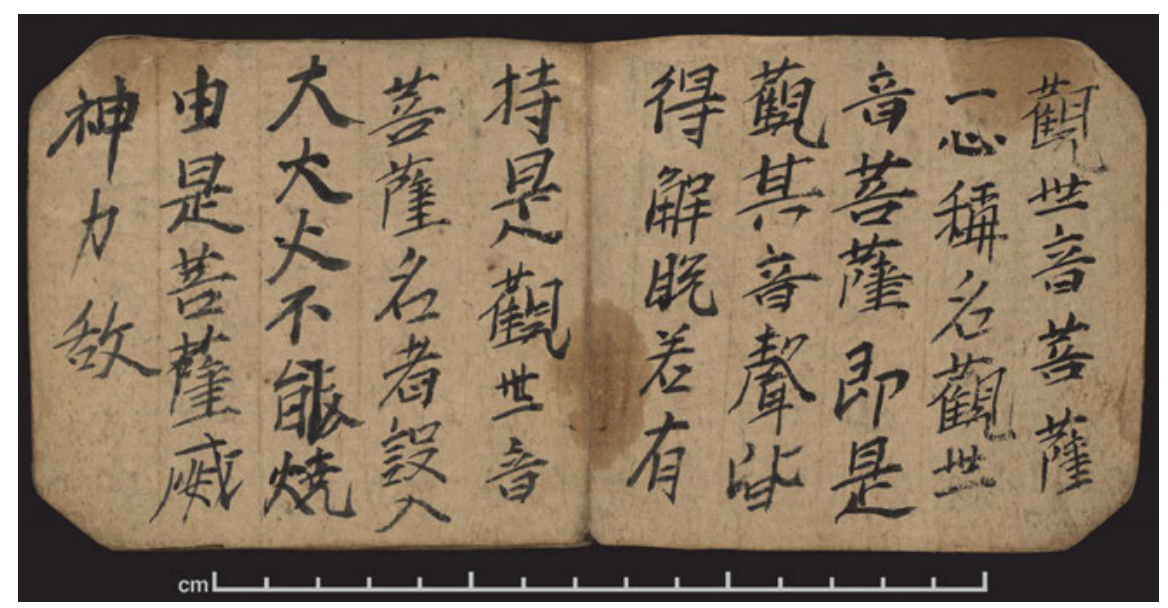

Fig. 6: A bifolio from codex S.5442, showing the bevelled corners. $(10 \times 10.8 \mathrm{~cm}$; The British Library)

83 See the stunning examples of Manichaean book art in Gulácsi 2005.

84 On Dunhuang manuscripts with illustrations, see Drège 1999a; also Fujieda 1968.

85 Budge 1977, ix puts forward a similar theory about a Coptic Biblical papyrus codex from the late third or early fourth century. 
On the whole, based on their content, we can divide the Chinese codices from Dunhuang into two main types. The first are those with primers and texts of an educational nature, such as the Qianziwen 千字文 (e.g. P.4809, P.3062), Kaimeng yaoxun 開蒙要訓 (e.g. S.5431, S.5464), Kongzi Xiang Tuo xiangwen shu 孔子項託相問書 (e.g. P.3833, S.5529), as well as the poems of Wang Fanzhi 王梵 志 (d. ca. 670; e.g. P.3833, P.4094), Wei Zhuang 韋莊 (ca. 836-910; e.g. S.5477, P.3910) and other popular poets. These codices must have belonged to students and were related to educational practices. ${ }^{86}$ The other main category includes booklets with Buddhist texts, including ritual manuals, popular scriptures or a series of them. They certainly do not form a homogenous group as they include both single- and multi-text manuscripts. ${ }^{87}$ Among the noteworthy single-text examples are the booklets with the Diamond sutra (Ch. Jingang bore boluomi jing 金剛般若波羅密經, Skt. Vajracchedikā-prajñāpāramitā-sūtra) copied by an old man in his eighties from a printed edition from Xichuan 西川..$^{88}$ According to the colophons, the old man transcribed these copies 'for circulation among the faithful' 流傳信士, ${ }^{89}$ exhibiting a wish to benefit all living beings, without directly pushing any personal agenda to the foreground. ${ }^{90}$ This type of devotional aspiration was, of course, an important part of Mahāyāna Buddhism and served as a major motivation for the production of manuscripts and art.

It is not hard to see that there are some fundamental similarities between pothis, concertinas and codices from Dunhuang. They are all booklet-type forms that appeared in Dunhuang after the region lost direct connection with the Tang and developed closer ties with Tibetan and Central Asian cultures. In a sense, they are tokens of the new cultural contacts of the region. Although bound differently, concertinas and codices often featured pages in the shape of pothi leaves, which could well have been a conscious effort to emphasize the connection with palm-leaf manuscripts of the Buddhist past.

86 Student manuscripts are to be examined in the next chapter.

87 Occasionally, manuscripts contain a combination of educational and religious texts, such as codex S.5464, which contains the primer Kaimeng yaoxun followed by two empty pages and the Jingang jing zan 金剛經讚 (Eulogy on the Diamond sutra).

88 There is quite a bit of secondary literature on this group of manuscripts, e.g. Wen Chu 1990; Teiser 1994, 121-128 and 224; Zheng Acai 1998, 36. For the Diamond sutra in Dunhuang in general, see Hureau 2014.

89 See, e.g. Giles 1940, 320.

90 For an overview of the motives for making donations in Guiyijun Dunhuang, see Sørensen 2020a, 6-7. 


\subsection{Multiple-text manuscripts with short scriptures}

In addition to their physical likeness, a group of codices and concertinas stand out due to their comparable content. The physical and textual correspondences between these manuscripts justify treating them as a specific group. ${ }^{91}$ They usually contain a series of Buddhist scriptures from a relatively limited pool of texts, including the Guanyin jing 觀音經 (Scripture of Guanyin, i.e. the $25^{\text {th }}$ chapter of the Lotus sutra), ${ }^{92}$ Molizhitian jing 摩利支天經 (Sutra of Marīi-deva), Dizang pusa jing 地藏菩薩經 (Sutra of Bodhisattva Kșitigarbha), Foshuo xuming jing 佛說續命經 (Sutra Spoken by the Buddha on Prolonging Life), Foshuo yan shouming jing 佛說 延壽命經 (Sutra Spoken by the Buddha on Extending One's Life-span), and the Bore boluomiduo xin jing 般若波羅蜜多心經 (Prajnāpāramitā-hṛdaya-sūtra, i.e. Heart sutra). Several of these short Buddhist texts are apocryphal scriptures composed in China. ${ }^{93}$

From the point of view of their physical characteristics, some concertinas have a slightly stiffer cover, which may also include a silk wrapping. Similarly, the cover of codices is often firmer than the rest of the pages but, on the whole, the manuscripts are still relatively limp. ${ }^{94}$ As mentioned before, many of the codices retain traces of having been folded in half along a vertical axis. Significantly, multiple-text manuscripts in this group are typically small, sometimes the size of a credit card or even smaller. There are several manuscripts with dimensions smaller than $5 \times 5 \mathrm{~cm}$, which implies a fundamental difference in terms of their use and function, when compared with Buddhist scrolls that constitute the overall majority of the Dunhuang corpus. The smallest booklets imply not only portability but perhaps even an effort to make them as unobtrusive as possible. Almost too small to be read comfortably, they may have been used as amulets, sewn into clothes, or placed inside containers.

91 There are, of course, many other types of manuscripts that contain multiple texts, such as ritual texts, meditation texts, doctrinal works, poems, hymns, spells or excerpts from scriptures, etc. The ones discussed here represent a subset with shared a) physical characteristics and b) textual content.

92 The title Guanyin jing is the abbreviation of a much longer one that usually appears at the start of the text in manuscripts. On this, see below.

93 Featuring 2,000 plus characters, the Guanyin jing is the longest. The Foshuo xuming jing, for example, is merely 235 characters, including its head and end titles. For a useful discussion of the Molizhitian jing in Dunhuang manuscripts and art, see Zhang Xiaogang 2018.

94 In some instances, the cover folio comprises multi-layered sheets of paper, causing it to be stiffer than the rest of the folia in the manuscript. In general, codices from Dunhuang and other Silk Road sites in China do not have hard covers, which makes them similar to Western 'limp bindings', as described in Szirmai 1999, 285-319. 
An important clue regarding the function of these multiple-text manuscripts can be derived from the pictures contained in some of them. Occasionally, the manuscripts include a picture of the donors, thereby emphasising their votive nature. For example, the opening pages of manuscript P.3932 have a drawing of two donors worshipping Bodhisattva Guanyin (Fig. 7).

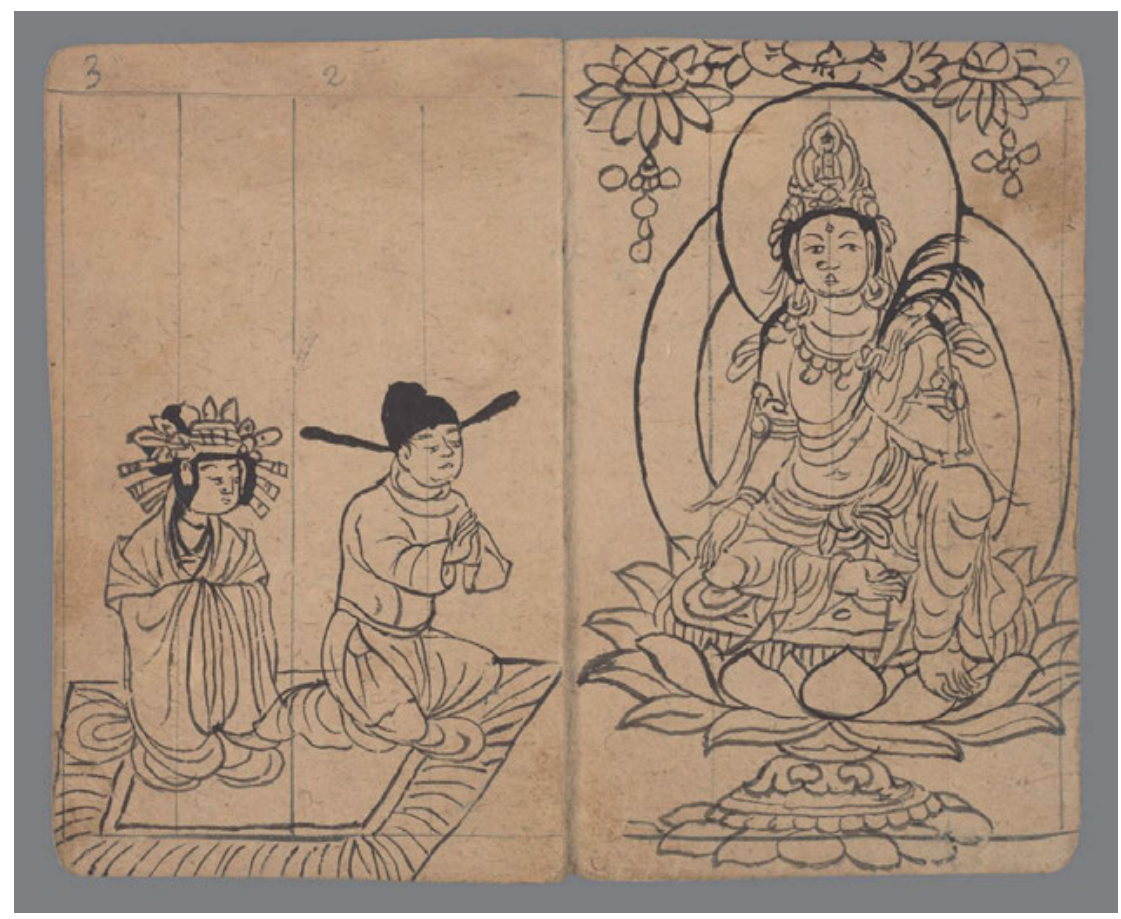

Fig. 7: The image of donors worshipping Bodhisattva Guanyin at the beginning of P.3932. $(12 \times$ $7.4 \mathrm{~cm}$; Bibliothèque nationale de France)

The donors appear to be a husband and wife, kneeling on a carpet on the left side of the composition, their faces turned towards the bodhisattva on the right. The husband puts his palms together, while the wife clasps her hands inside her sleeves. Guanyin is seated on a raised lotus pedestal, holding a willow branch in his left hand. On the top of his head is a miniature figure of Amitābha Buddha, a typical iconographic feature. The picture portrays the donors turning to the bodhisattva for help, just as the Guanyin jing, the first text in the manuscript, advocates in times of hardship. They are pleading for the support and protection of the compassionate bodhisattva to deliver them from calamity or misfor- 
tune. It is likely that a specific experience in the donors' lives, illness or death, was the immediate motivation for the manuscript's production. ${ }^{95}$

An analogous composition, but of a considerably less skilled hand, decorates the beginning of Stein painting 209, a miniature codex $(6.2 \times 6.3 \mathrm{~cm})$ in the British Museum. ${ }^{96}$ Here, the text is the Foshuo xuming jing (Sutra Spoken by the Buddha on Prolonging Life), written similarly in a decidedly unskilled hand (Fig. 8). ${ }^{97}$ The picture shows a donor worshipping a standing deity with a flaming halo. The scripture mentions Amitābha Buddha, as well as Bodhisattvas Guanyin and Dashizhi 大勢至 (Skt. Mahāsthāma-prāpta), making it highly likely that the figure depicts one of them. Despite the unskilled manner of the drawing, the flaming background and the overall composition of a devotee standing in front of the deity suggest the figure could be Guanyin. The bodhisattva has short, stick-like legs characteristic of a child's drawing, although the age of the 'artist' is uncertain. The donor figure is equally problematic, especially for his headwear that makes him look like a rabbit with long ears.

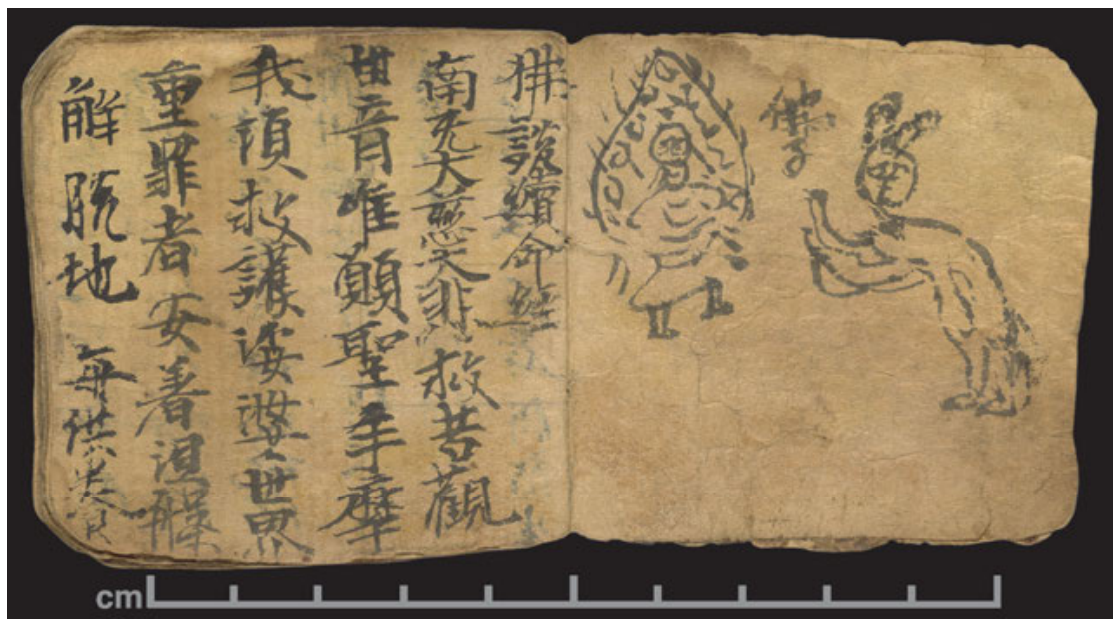

Fig. 8: Stein painting 209 with a line drawing of a donor with a bodhisattva. $(6.2 \times 6.3 \mathrm{~cm}$; The British Museum)

95 See below on the textual structure of this manuscript.

96 Most of the Stein manuscripts originally deposited in the British Museum are now kept in the British Library. Probably due to the drawing, this small codex is one of the few manuscripts that remain in the British Museum along with paintings and other art objects. This is why its pressmark starts as "Stein painting," even though it is a manuscript.

97 On the Foshuo xuming jing in Dunhuang, see Li Xiaorong 2010. 
Due to the ineptness of the drawing, it is virtually impossible to decipher what it intends to depict without parallels in other manuscripts. In fact, when first introducing this booklet, Aurel Stein described the drawing as a 'sketch of demons or monsters'. ${ }^{98}$ It has been suggested that the worshipper may have been a child as his hair seems to be in two tufts, characteristic of young boys. ${ }^{99}$ This is, of course, a possibility but a comparison of the drawing with the one in P.3932 above suggests that it depicts a donor with joined palms worshipping the bodhisattva. There is, however, no solid evidence to confirm that the donor in the picture is a child.

The manuscript is in a classic codex form with folded bifolia sewn together into quires. As can be seen in Fig. 8, the corners are rounded and the pages are further trimmed so that most (but not all) have an arching bottom edge. The side edges arch slightly inward and the top edges are straight. The trimming must have been done after copying the text, as it affected some characters near the bottom of the pages. The crudeness of the trimming is consistent with the quality of the drawing and the handwriting, and probably represents the efforts of the same person. Somewhat unexpectedly, the sewing is done well, and the thread holds the quires together tightly (Fig. 9). For this reason, it is not inconceivable that the sewing was re-done later by conservators at the British Museum, possibly using the original thread.

Technically speaking, this manuscript is not a multiple-text manuscript as it only contains a single text. The reason it is being adduced here is primarily due to the drawing of the donor at the beginning. Nonetheless, the codex consists of 8 bifolia, excluding the front and back covers, amounting to a total of 30 pages.

98 Stein 1921, v. 2, 977.

99 Whitfield and Farrer 1990, 99. Headwear with similarly raised flaps appears in a painting of an adult donor in P.4518 (2). 


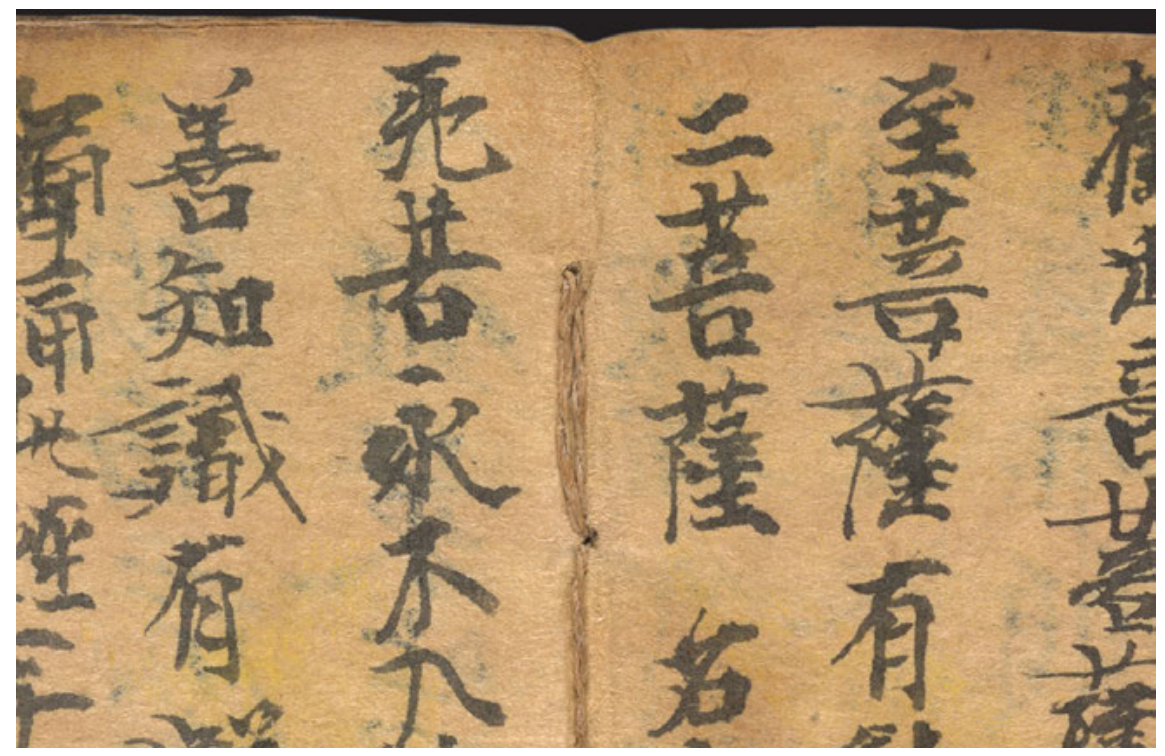

Fig. 9: The thread that binds the quires together in Stein painting 209.

Of these, the drawing and the text only take up the first 7 pages, the remaining 23 pages are blank (Fig. 10). ${ }^{100}$ In other words, only about a quarter of the manuscript has text in it, all the other pages are blank. It would be naive to think that the individual who produced the codex, regardless of the quality of his or her handwriting, misjudged the length of the Foshuo xuming jing to such an extent. Instead, it is more likely that either the same individual, or someone else, intended to add additional texts to the booklet. The incompleteness of the manuscript shows that the texts in such multiple-text booklets may have been copied on different occasions. Weeks or months may have passed between the copying of individual sections, which also partly explains why most multiple-text manuscripts feature more than one hand. ${ }^{101}$

100 Unfortunately, this manuscript has not been published in full form and even the digital images on the IDP website are selective and include only the inscribed pages, thus creating the impression of a very thin booklet filled with text.

101 Another example of the same type of incomplete multiple-text manuscript is S.5678, a glued codex with the Guanyin jing. In addition to this text, the very last page, which now also functions as the back cover, contains the title and the first seven characters of the Foshuo yan shouming jing. The rest of the page is blank, even though enough space was available to write two more lines. As there are traces of one or more bifolia torn off from the end, the missing 


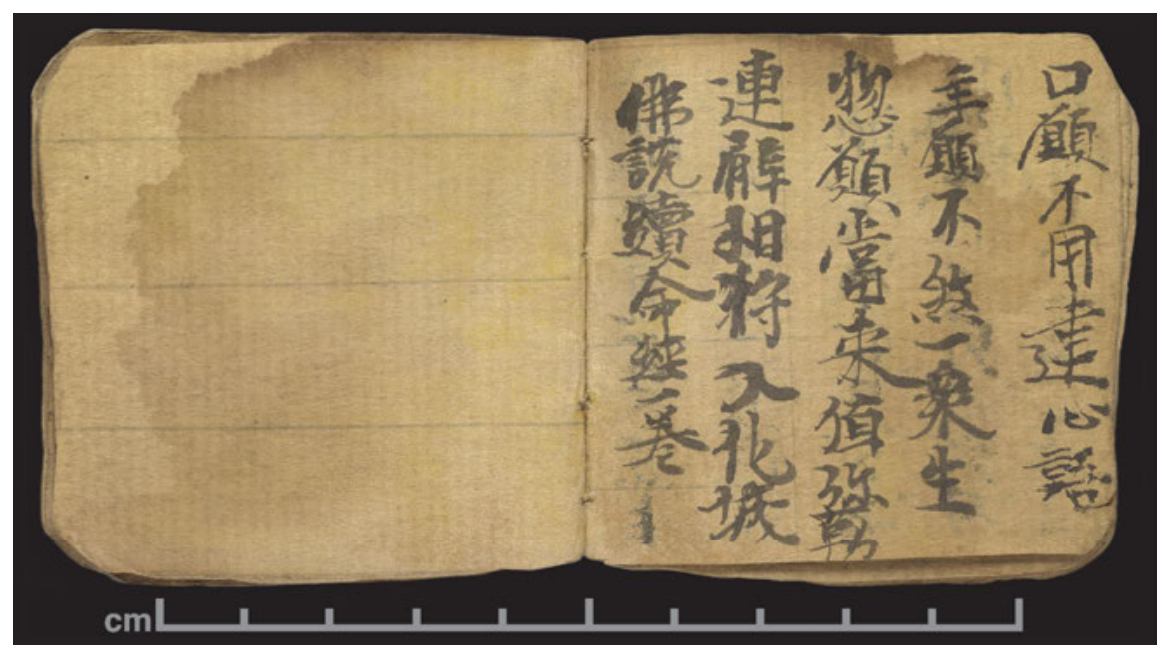

Fig. 10: The end of the text in Stein painting 209, showing the horizontal ruling lines from the original scroll.

In discussing this manuscript, Stein pointed out that the manuscript paper had originally been ruled for a scroll but was then cut into pieces and sewn into a codex. It was not uncommon to reuse sheets from older Buddhist scrolls to create codices, only in this case the source paper was blank, save for the ruling lines. Indeed, the ruling lines make it clear that the producer of this codex did not simply use a standard-size sheet of paper but disassembled a scroll already ruled for writing. As we can see in Fig. 10, some pages have horizontal ruling lines, confirming that in the codex some sheets were turned sideways. On the side covered in writing, we can faintly see the original scroll's top or lower margin, which is now vertical. The width of the spread-out bifolia is about $12.6 \mathrm{~cm}$, that is, about half of the width (i.e. height) of the sheets of paper in Tangdynasty Buddhist scrolls. ${ }^{102}$

pages were probably also blank. Nevertheless, the title and the first few characters of the second text suggest that this codex was on its way to becoming a proper multiple-text booklet but was never finished.

102 The standard size of scrolls in the Tang is already pointed out in Fujieda 1966, 16. For an extremely useful detailed analysis of paper sizes in scrolls, see Drège 2002. 
Fig. 11 shows the steps of the process for creating the bifolia for the codex from a sheet of paper intended to be used in a scroll. ${ }^{103}$ Note the presence of ruling lines, which are also visible, but have no function, in the codex. In step 1 , the original sheet was cut in half lengthwise. Step 2 was to fold (see dashed line) one of the resulting narrower sheets in half, also lengthwise. In step 3, this folded narrow sheet was sliced crosswise into 8 pieces. These pieces formed the 8 bifolia of the codex, which were then stacked together into quires (step 4).
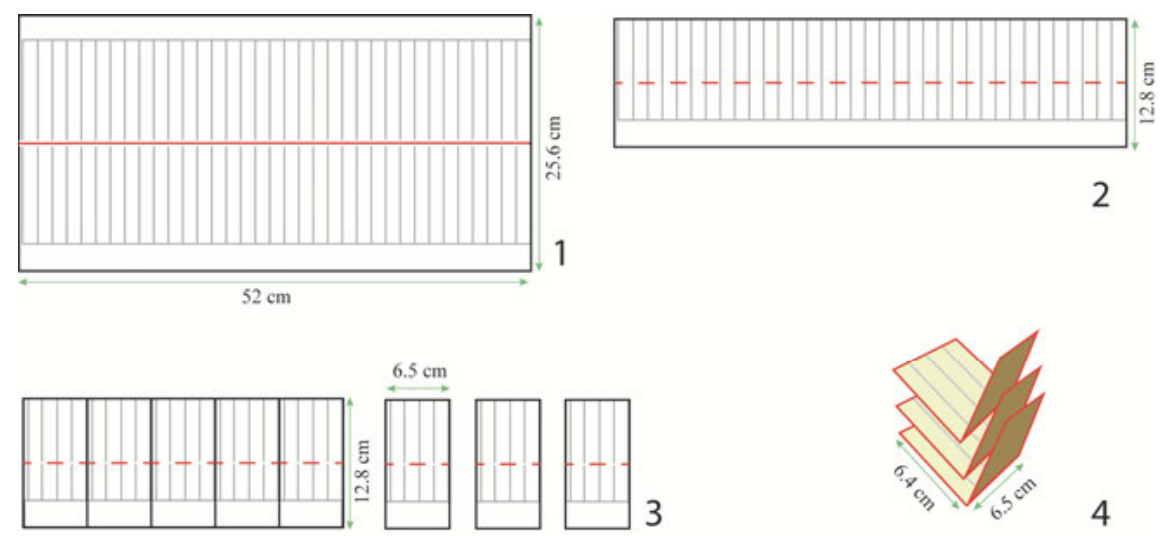

4

Fig. 11: Cutting and folding a sheet from a scroll to make a quire in a codex.

In fact, it may be deduced that the entire codex was assembled from a single sheet of paper that had originally formed part of a scroll. One sheet would have produced two such codices. The height of the pages in the codex at their highest point is ca. $6.2 \mathrm{~cm}$. Multiplying that by 8 , the number of bifolia in the codex, works out at $49.6 \mathrm{~cm}$, which is very close to the length of the individual sheets of paper in some Tang dynasty scrolls. Thus the codex was cut and folded from sheets ca. $25.2 \times 49.6 \mathrm{~cm}$ in size. ${ }^{104}$ These dimensions are very different from the sheets in scrolls from the ninth and tenth centuries, which were typically 40-45 $\mathrm{cm}$ long. According to Jean-Pierre Drège's study documenting the size of sheets in dated scrolls from the Stein and Pelliot collections, this size is characteristic

103 For simplicity and clarity, only the highest value of the dimensions in Fig. 11 is given (i.e. $12.8 \mathrm{~cm})$.

104 Multiplication inevitably introduces a degree of imprecision. 
of sheets used in scrolls from around the 690s until the end of the eighth century. ${ }^{105}$ There are both Buddhist and Daoist scrolls with sheets of similar size from this period. Among Buddhist texts in particular, the closest match is S.4989 $(25.2 \times 49 \mathrm{~cm})$ with the Jinguangming zuisheng wang jing 金光明最勝王經 (Sutra of the Supreme King of Golden Light, Skt. Suvarna(pra)bhāsottama-sūtrendrarāja) and a colophon dated to 703 .

The codex being assembled from a single sheet of paper that had originally been part of a scroll presents an intriguing phenomenon as it entails a direct conversion from one scroll sheet to two small codices. Nothing was left out and nothing added, the entire sheet was consumed for the production of two codices. There seems to be some significance in this perfect conversion from one book form to the other, making it extremely unlikely the paper sheet was recycled purely as a writing support. Tang dynasty Buddhist scrolls prior to Dunhuang's separation would have unquestionably had a religious, social and potentially political import during the Guiyijun period. Reusing the sheets of such scrolls for the production of new codices must have been a deliberate procedure whereby the original scroll not only retained part of its efficacy but may have acquired new significance. ${ }^{106}$ This would have been true even if the original sheet had no writing on it, as is the case with Stein painting 209.

In the above two examples, the picture at the beginning of the codex depicts the donors, showing them in the pious act of worship in front of Guanyin. The self-referential images clarify that the making of the booklet constituted an offering (gongyang 供養), through which the donors requested the bodhisattva's help. The Guanyin jing prescribes the verbal act of calling out the name of Guanyin, rather than just focusing one's mind on him, and this tallies well with the predominantly textual content of these manuscripts. By carrying a copy of this chapter of the Lotus sutra along with other texts on them, the owners would have continuously enjoyed the bodhisattva's protection without explicitly having to call out his name.

105 For the height of the sheet, I use the maximum width of the spread bifolia (i.e. $12.6 \mathrm{~cm}$ ) multiplied by two. Any variation in the width of the bifolia would have been the result of trimming that occurred after the codex had been assembled.

106 This is also apparent in the case of Uighur codices from Turfan, which at times consist of folded paper from Chinese sutras written around the fifth and sixth centuries. For the related phenomenon of reusing personal letters of the deceased to write Buddhist scriptures as a way of mourning in medieval Japan, see O’Neil 2019. 


\subsection{Manuscript S.5531}

A further example is manuscript S.5531 from the Stein collection at the British Library. It is a small codex $(12.5 \times 7.3 \mathrm{~cm})$, approximately the size of a modern passport, only slightly narrower. It matches the size of manuscript P.3932 above, pointing to similarities in their function and background. Aside from the last two pages, the paper is ruled throughout the manuscript, delineating each page into four vertical columns. The top and bottom margins are about $0.5-0.8$ $\mathrm{cm}$ wide, while the side ones are slightly wider. The consistency of the layout indicates that the entire manuscript was carefully designed. There were no subsequent additions to the original structure. Typical of Chinese manuscripts of this period, it is written with a pen, rather than a brush. The back of the codex is darker in colour, even though its other side (i.e. the last page of the manuscript) matches the colour of the other leaves.

Structurally, the manuscript consists of 32 bifolia, folded in half and assembled into four quires of equal size. Thus, each quire has 8 bifolia sewn together with a white thread, through four sewing holes pierced along the centrefold at a roughly even distance from each other. ${ }^{107}$ The beginning of the book is missing, and the text begins in mid-sentence. The missing portion of the text (i.e. Guanyin jing), including the title, amounts to 1,119 characters, which-based on the 45 character per page format of the extant pages-constitutes approximately 25 pages. This is slightly over 6 bifolia, thus it is possible the first quire was smaller than the remaining ones with 8 bifolia each. It is more likely, however, that the codex opened with a series of spells and a picture of donors, and the first quire matched the size of the extant four.

The inside of the back cover (Fig. 12) has the date "the twentieth day of the twelfth month of the gengchen year' 庚辰年十二月廿日, the year probably corresponding to 921, as Lionel Giles, the first cataloguer of the Stein collection, proposed. ${ }^{108}$ As the year is given according to the sexagesimal cycle (i.e. tiangan dizhi 天干地支) without a concrete reign title, theoretically it could also refer to 861 or 980 , both of which fall within the Guiyijun period when these types of codices were in use. Nevertheless, they were much more common towards the first half of the tenth century, hence the conjecture of 921 is probably accurate. As a continuation of the Tibetan practice, dating colophons with cyclical signs

107 There are also remnants of some red, blue, and green threads in the second and third quires. It is unclear whether the colours had any significance beyond ornamentation.

108 Giles 1957, 85. Below the date, slightly to the right is the red seal of the British Museum, which initially housed the Stein collection of Dunhuang manuscripts. 
without reign titles is also typical of this period. ${ }^{109}$ In his inventory of colophons in Chinese manuscripts, Ikeda On accepts this dating, identifying the gengchen year as 920. This was true for most of the year, yet according to the Gregorian calendar, the twentieth day of the twelfth month would have technically been at the beginning of the following year. ${ }^{110}$

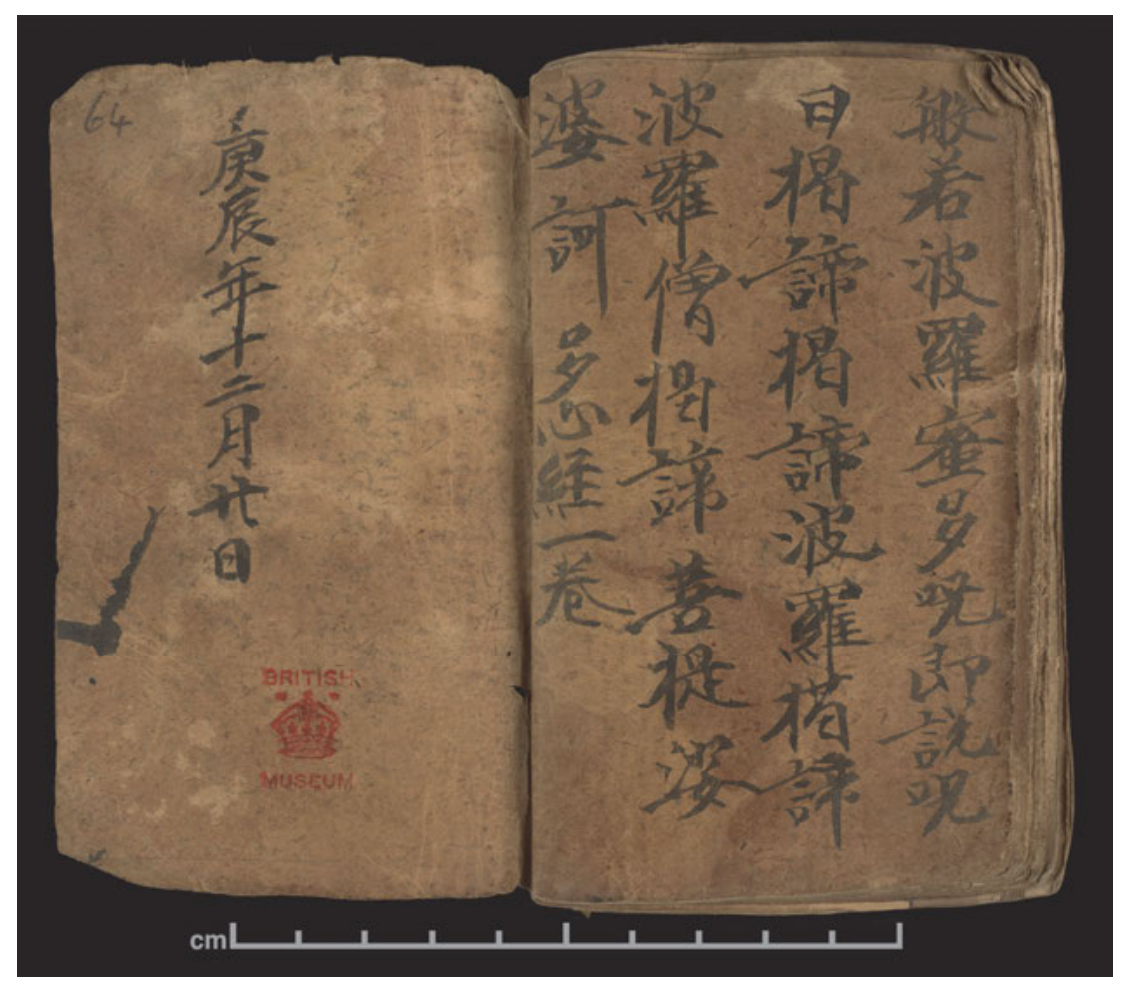

Fig. 12: The inside back cover of manuscript S.5531 with the date (left) and the end of the Heart sutra (right). $(12.5 \times 7.3 \mathrm{~cm}$; The British Library)

109 See, for example, Zhang Xiuqing 2007 and 2008.

110 Ikeda 1990, 464. 


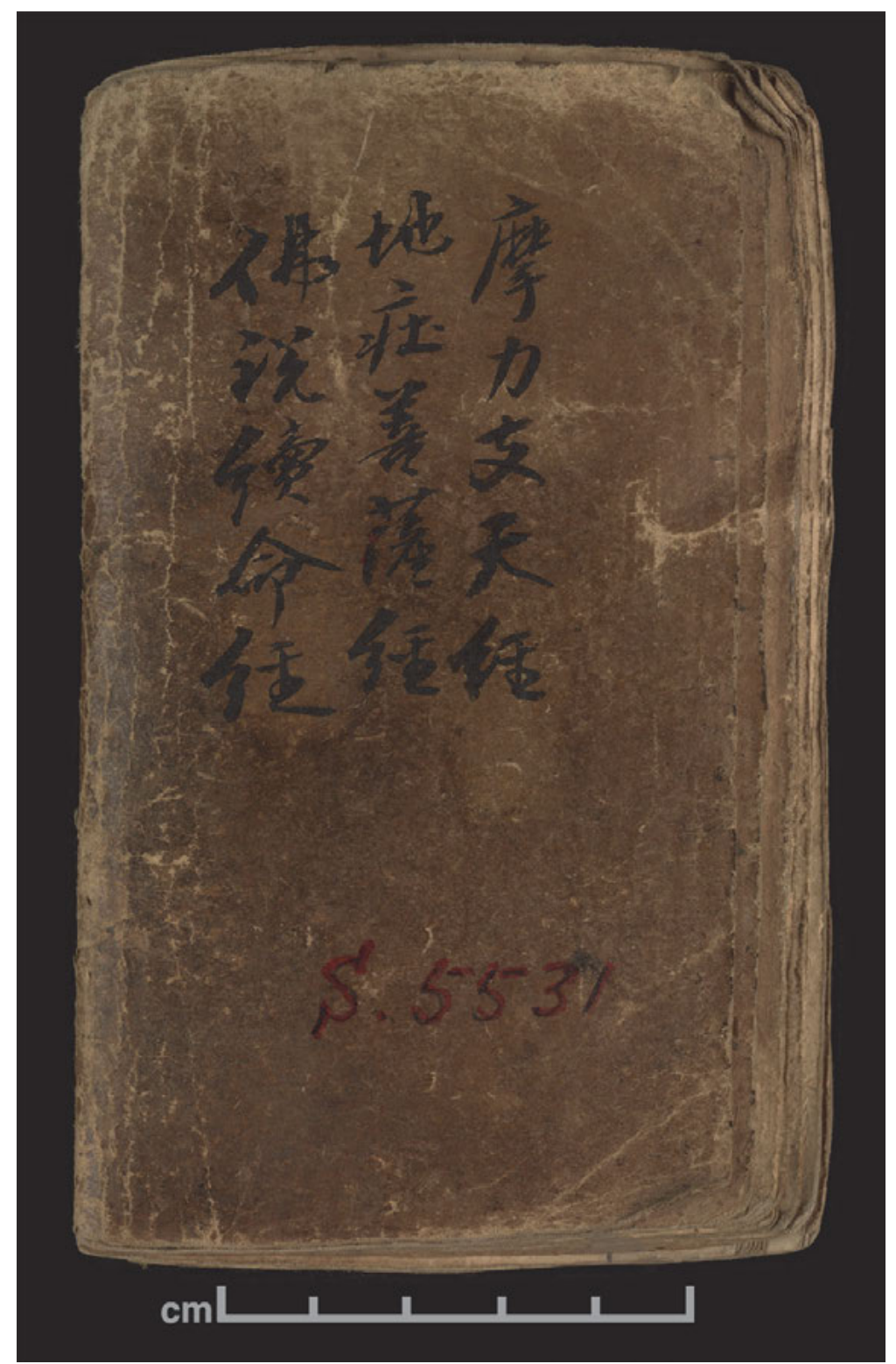

Fig. 13: The back cover of S.5531 with the titles written by Stein's secretary. 
On the back cover of the booklet (Fig. 13), we find the title of three scriptures in the hand of Stein's Chinese secretary Chiang Ssu-Yeh (i.e. Jiang Xiaowan 蔣孝琬, 1858-1922). ${ }^{111}$ Not recognising Chiang's handwriting, I initially thought these three titles were a form of an early 'table of contents'. ${ }^{112}$ Yet a comparison with titles written on other manuscripts confirms that it was Chiang who wrote the three titles on the back of S.5531. He commonly recorded titles or brief descriptions directly on the scrolls, to which he usually appended numbers in red ink using the so-called Suzhou numerals 蘇州碼子, a traditional numeral system commonly employed during the nineteenth and early twentieth centuries for accounting and other number-intensive tasks. Sometimes Chiang's description is unmistakably vernacular, as in S.1286, on which he wrote 'worn and torn piece (i.e. fragment) of the Foming jing' 破爛佛名經一塊. ${ }^{113}$ Chiang's hand was not immediately apparent in manuscript S.5531 because the titles are not accompanied by the conspicuous red numerals. Chiang's titles on the back cover read as follows:

1. Molizhitian jing 摩力支天經 (<Molizhitian jing 摩利支天經; Sutra of Marīcideva)

2. Dizhuang pusa jing 地莊菩薩經 (<Dizang pusa jing 地藏菩薩經; Sutra of Bodhisattva Kṣitigarbha)

3. Foshuo xuming jing 佛說續命經 (Sutra of Extending Life)

In the first two titles, Chiang miswrote the character $l i$ 利 in the name of Marīci and the character zang 藏 in the name of Kșitigarbha with phonetically similar substitutes (i.e. li 力 and zhuang 莊). As both other manuscripts and later inscriptions testify, using the character 力 to write the second syllable was a possible, if uncommon, way of transcribing the name of Marīci in Chinese. ${ }^{114}$ In Chiang's case, however, this was simply a mistake due to his complete unfamiliarity with Bud-

111 Stein always wrote about Chiang with affection and respect; see, for example, Stein 1912, v. 1, 114-117, Stein 1921, v. 2, 578. See also Wang Jiqing 2013, Ren and Wang 2014.

112 Galambos 2019, 42-44.

113 Although this work has up to now not been carried out, the systematic study of Chiang's notation in the manuscripts could potentially lead to insights into the original arrangement of the manuscripts in the library cave. See Fang Guangchang 1995 and Fang Guangchang 2006, 218.

114 This phenomenon was naturally limited to dialects in which the final stops of enteringtone characters became lost. For example, the Quan Liao wen 全遼文 (Chen Shu 1982, 248) records an inscription dated to 1096 from a stūpa in Jizhou 薊州 (modern-day Tianjin 天津), which mentions obtaining relics of the Buddha at a place called Molizhitian Cliffs 摩力支天佛 厓, with the name of Molizhitian written in the same way as in Chiang's note. 
dhist literature. The three titles he wrote on the back of the manuscript must have been a quick reference note, rather than an actual table of contents, especially as the manuscript contains several other texts. Most of these are explicitly marked with a title, showing they did not function as parts of a new composite text but remained separate textual entities, appearing together in a manuscript only temporarily. Moving through the booklet from the beginning, we find ten distinct texts, identified with the following titles: ${ }^{115}$

1. [Miaofa lianhua jing Guanshiyin pusa Pumen pin di nianwu 妙法蓮華經觀世 音菩薩普門品第廿五] (Sutra of the Lotus of the Wonderful Dharma, Chapter 25: The Universal Gateway of Bodhisattva Guanshiyin)

2. Foshuo jie baisheng yuanjia tuoluoni jing 佛說解百生怨家陀羅尼經

(Sutra Spoken by the Buddha on the Dhāraṇī for Dispelling Resentment Accumulated in the Course of a Hundred Lifetimes)

3. Foshuo Dizang pusa jing 佛說地藏菩薩經 (Sutra Spoken by the Buddha on Bodhisattva Kșitigarbha)

4. Foshuo tianqingwen jing 佛說天請問經 (Sutra Spoken by the Buddha on Questions Asked by a Deity)

5. Foshuo xuming jing 佛說續命經 (Sutra Spoken by the Buddha on Prolonging Life)

6. Molizhitian jing 摩利支天經 (Sutra of Marīci-deva)

7. Foshuo yan shouming jing 佛說延壽命經 (Sutra Spoken by the Buddha on Extending One's Life-span)

8. Shaosheng sanke 少乘三科 (Three Categories of the Lesser Vehicle)

9. Foshuo Yanluo wang shouji sizhong nixiu sheng qizhai gongde wangsheng jingtu jing 佛說閻羅王授記四眾逆修生七齋功德往生淨土經 (The Scripture Spoken by the Buddha to the Four Orders on the Prophecy Given to King Yama Concerning the Merits of the Seven Feasts to be Cultivated in Preparation for Rebirth in the Pure Land)

10. Bore boluomiduo xin jing yi 般若波羅蜜多心經一 (Prajñāpāramitā-hṛdayasūtra, in one ...)

115 For the sake of transparency and easier comparison, I include the Chinese characters in the lists of titles even if they have already occurred. 
The texts in the codex feature a so-called 'head title' (shouti 首題) located at the very beginning and, in most cases, an 'end title' (weiti 尾題). This was a typical way of marking the beginning and end of texts in Chinese scribal culture, in both single- and multiple-text manuscripts. The two titles did not necessarily match, as the head title normally used the official and complete appellation, while the end title could be an abbreviated or less formal way of referring to the text. ${ }^{116}$ Thus text No. 9 has an extremely long head title but its end title is the much more manageable Foshuo Yanluo wang jing yi juan 佛說閻羅王經一卷 (Sutra Spoken by the Buddha on King Yama, in one juan). ${ }^{117}$ It seems to have been a consistent rule for the type of multiple-text manuscripts discussed in this chapter that they included the phrase yi juan 一卷 ('in one juan') in the end title but not in the head title. ${ }^{118}$

Item No. 1 is the Guanyin jing, that is, the $25^{\text {th }}$ chapter of the Lotus sutra in Kumārajīva's translation, an extremely popular text during the medieval period both in Dunhuang and elsewhere. It survives in over a hundred manuscripts, some with colour illustrations. ${ }^{119}$ As a result of its immense popularity and independent circulation, the chapter was also commonly referred to by a standalone title, further emphasizing its self-contained status. ${ }^{120}$ As the first quire of the manuscript is missing, no head title is present, although we can confidently reconstruct this from other similar manuscripts, which show little variation in this regard. Hence the title is shown in the list in brackets. The end title reads Miaofa lianhua jing yi juan 妙法蓮華經一卷 (Sutra of the Lotus of the Wonderful Dharma, in one juan), which in other manuscripts is more commonly written as Guanyin jing yi juan 觀音經一卷 (Scripture of Guanyin, in one juan). ${ }^{121}$ The end title appears on a new line which is followed by an empty line to separate the text visually from the one that follows it (Fig. 14).

116 This convention of head and end titles continues largely unchanged into the printed tradition during the following centuries.

117 For a careful study of this scripture and its role in the lives of people in Dunhuang and in medieval China in general, see Teiser 1994.

118 I am grateful to Nadine Bregler for drawing my attention to this phenomenon. This is an intriguing pattern because it holds true even for scriptures that are merely a few lines long (e.g. the Heart sutra) and thus should not really amount to a whole juan. Evidently, the measure word juan is used in such cases as a purely textual unit and no longer retains its original sense of a 'scroll'.

119 Yü 1994, 152; see also Fujieda 1968 and Drège 1999a.

120 For a brief overview of the Guanyin jing in Dunhuang, see Fang Guangchang 1997, 225-227 and Drège 2014e.

121 See, for example, manuscript P.3932 below. 


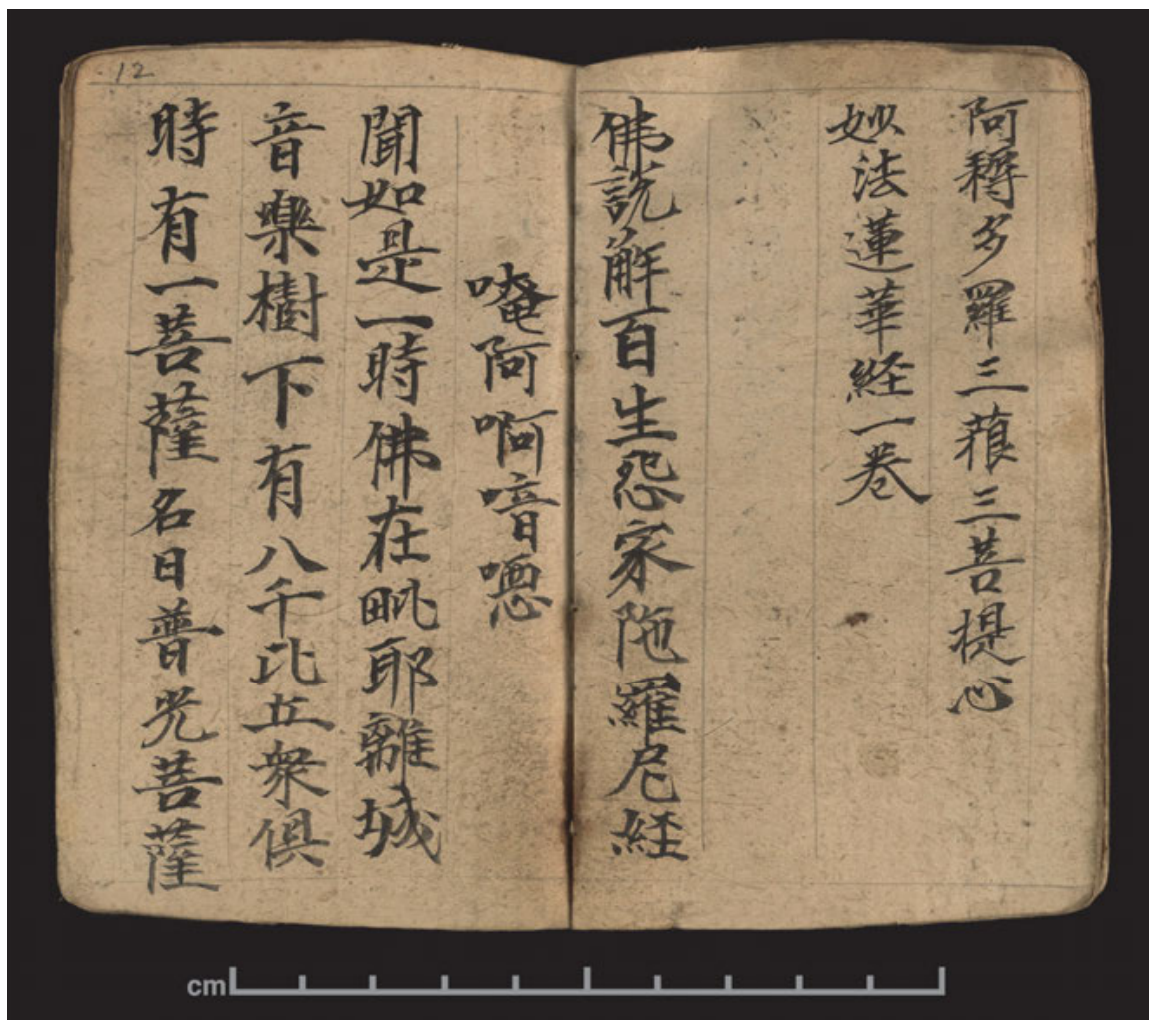

Fig. 14: The division between the first and the second texts in manuscript S.5531, marked with an empty line (third line from the right).

The next text in the codex is the Foshuo jie baisheng yuanjia tuoluoni jing (Sutra Spoken by the Buddha on the Dhāranī for Dispelling Resentment Accumulated in the Course of a Hundred Lifetimes), a collection of magical spells. It begins with a full title on a separate line, but the end title is missing. In its place, the text concludes with a short spell on an indented line. ${ }^{122}$ There is no empty line here to mark the end of the text but the indentation of the final line with the spell and the blank space following the head title of the following text provide a sufficient visual break to identify the boundary. Later in the manuscript, the titles do not always occupy a separate line yet there is almost always enough

122 There is a similar spell on an indented line at the beginning of the text, following the head title (see Fig. 14). 
indentation or empty space to indicate the division. The very last text (No. 10) in the codex is the Bore boluomiduo xin jing, more commonly known as the Xin jing 心經 or Heart sutra. The head title is written out in full but is surprisingly followed by the word $y i$ - ('one'). As the head titles in such manuscripts do not include the phrase yi juan 一卷 ('in one juan'), the person copying the text probably realised the mistake only after writing the character - which is why he stopped at that point. ${ }^{123}$ As expected, the end title includes the phrase and is written as Duo xin jing yi juan 多心經一卷 ([Prajñāpārami]tā-hṛdaya-sūtra, in one juan).

Text No. 8, the Shaosheng sanke 少乘三科 (Three Categories of the Lesser Vehicle), usually written as Xiaosheng sanke 小乘三科 (Three Categories of the Small Vehicle), consists of a series of questions and answers explaining Buddhist terms such as the Three Jewels 三寶, Four Noble Truths 四諦 and Five Aggregates 五蘊. This text occurs in over a dozen Dunhuang manuscripts, including P.2841 and P.3057. ${ }^{124}$ In our manuscript, the head title merges into the text without any visible separation, making it difficult to identify as a title. The end is also not marked with an end title. As a result, Giles did not identify it in his catalogue as a proper text, describing it instead as 'questions and answers on Buddhist doctrine'. ${ }^{125}$

Although the beginning of the codex is missing, based on other manuscripts of similar structure, we can be fairly certain that the original booklet did not bear a title on the front cover. Most of the texts in it are known from transmitted literature and are also well attested in other manuscripts from the ninth and tenth centuries. The scriptures in the codex show some discrepancies with the received versions but in most cases the variants are inconsequential. A series of corrections confirms that the individuals copying the texts were conscious of mistakes and made an effort to eliminate them. They used a variety of devices ranging from common correction marks to subsequent insertion of longer strings of text. Among the more significant differences is that the Foshuo yan shouming jing 佛說延壽命經 is not the version in the Taishō Canon $(\mathrm{T} 2888,85)$ but a different text bearing the same title. This non-canonical version survives in

123 Once again, I thank Nadine Bregler for suggesting this scenario.

124 See Tanaka 1983, 357-389; cf. Magnin 1984, esp. 267. For possible Old Uighur connections, see Kitsudō 2012. According to Sam van Schaik (personal communication), there are also some Tibetan texts, represented in many manuscript copies, with similar content.

125 Giles 1957, 85. 
Dunhuang in numerous copies, including many of the manuscripts discussed in this chapter. ${ }^{126}$

Even though, as this chapter illustrates, the Dunhuang cave library yielded a series of similar manuscripts with analogous collections of texts, none of these match the combination and sequence of the ten texts in S.5531. Accordingly, despite its typological similarities to other members of the group of multipletext manuscripts, the booklet appears to be an ad hoc selection of texts predicated by the donor's personal preference. The codex form and its small size imply that the donor carried the manuscript around. The nature of texts in it, in turn, points to a talismanic or ritual function.

Comparing the codicological structure of the codex with its textual arrangement, we can see that the textual boundaries never overlap with those of the quires, indicating that the physical structure had essentially no relevance for how the texts were copied. In fact, text No. 4 begins half a page into the second quire, without any sign of trying to adhere to the quire division. Clearly, once sewn together, the quires formed an indivisible whole. ${ }^{127}$ This is comparable to the composition of scrolls, in which scribes seemed to pay little attention to the physical boundaries once the individual sheets of paper had been glued together into a continuous writing surface. ${ }^{128}$

The handwriting in the book is relatively uniform, although it is possible to discern several different hands. Table 2 compares characters $c i$ 此 ('this') and $w u$ 無/无 ('there is no; have no') across the ten texts in the codex. The examples show that, as a rule, the same character is written consistently within the same text but not necessarily in others. Allowing for the possibility that the same individual's handwriting could have varied according to his mood, amount of time available, his ability to focus or other factors, the examples in the table represent the work of at least four or five different hands. Taking character 此, for example, text No. 1 seems to represent one hand, texts Nos. 2 and 3 another one, texts Nos 5, 7 and 9 yet another one. The forms of the character 無/无 largely confirm this classification and fill in some gaps. The forms in texts Nos. 6 and 9 are the most compatible with each other, while the form in text No. 4 (i.e. 無)

126 It also survives in Tangut translation from Khara-khoto; see Zhang Jiuling 2018.

127 This holds true even if the text had been written before the bifolia were sewn together.

128 This does not mean that they wrote in an arbitrary manner, as the number of lines per paper sheet usually remained stable within the same scroll. Yet strictly speaking, the number of lines was set during the process of ruling the paper, and the individual copying the scripture simply followed the ruling without having to worry about the physical structure of the scroll. 
exhibits an entirely different orthographic structure. ${ }^{129}$ Thus the forms 無 and 无, even if appearing in the same manuscript, were written by different individuals. Finally the thick strokes of the forms in text No. 10 are distinct from those in all other texts. In sum, the texts in the codex are in five distinct hands, which demonstrates that in practical terms, the production of the manuscript entailed a much more elaborate process than one individual simply copying a series of Buddhist scriptures in succession.

Tab. 2: Comparison of characters 此 and 無/无 in the ten texts in manuscript S.5531.

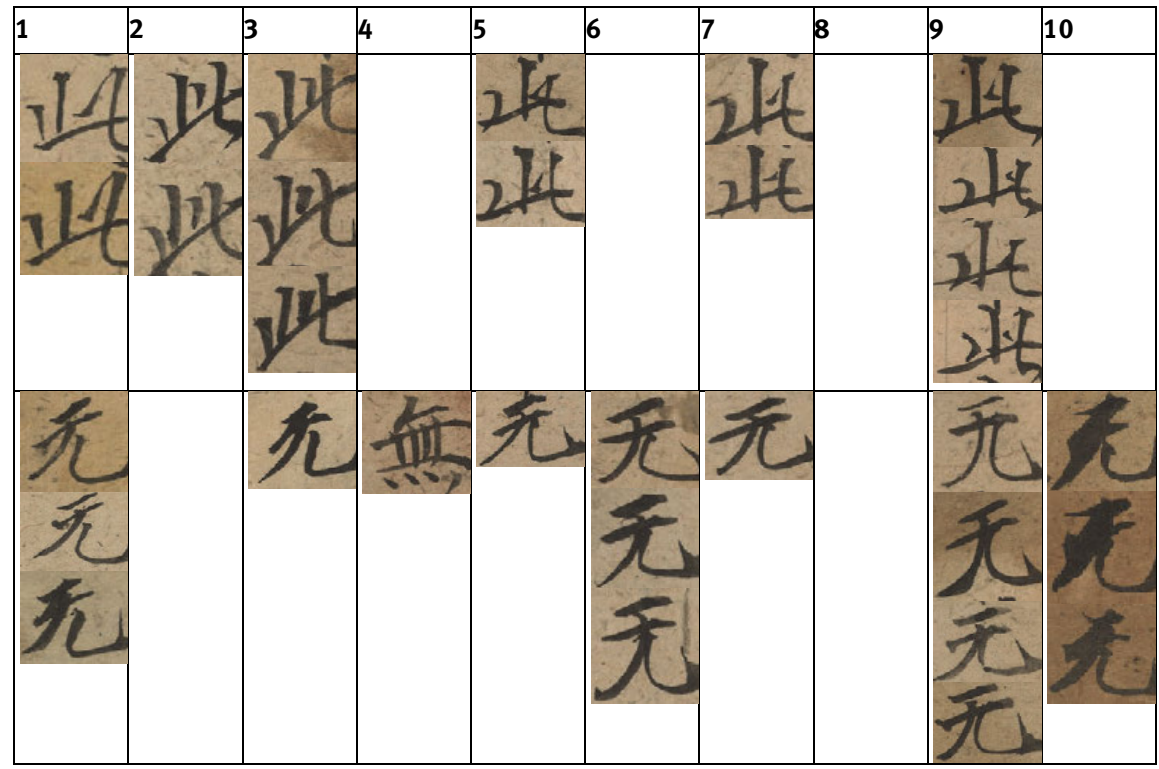

The size of characters (not apparent in the table) is yet another indication of different hands. The last text, for example, is written in substantially larger characters, with about 8-9 characters per line instead of the 10-13 found in the rest of the manuscript (see Fig. 15). In addition to being in a distinct hand, the larger character size sets it apart from the rest of the texts. While the differences in the quality or size of characters may appear a trivial observation, they reveal the involvement of several people in copying relatively small amounts of text

129 The term 'orthography' is used here in reference to character structure, without advocating whether particular character forms conform to, or are different from, an officially sanctioned standard. 
into the same booklet. This, in turn, is of significance for understanding the process of the production of the entire manuscript, as well as its potential function. As will be argued below, this particular codex probably represents the collective work of several individuals, possibly from the same family, acting as donors together. Rather than having a single donor making an offering on behalf of the whole family, it seemed important that each individual copied several pages in their own hand, thereby becoming involved personally-and physically-in the act of offering.
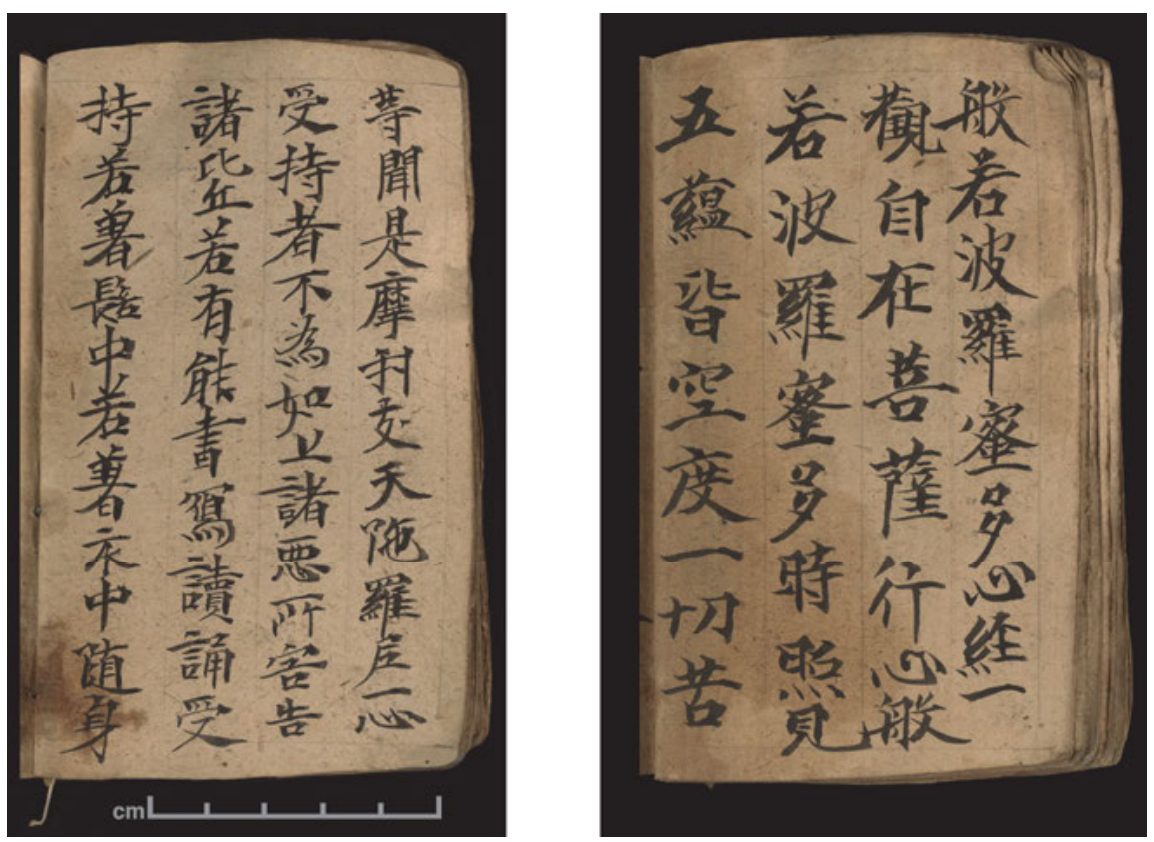

Fig. 15: Comparison of handwriting and character size in text No. 6 (left) and text No. 10 (right) in manuscript S.5531.

It is also significant that although each individual could have made an offering by copying an entire manuscript on their own, instead they each copied a small portion of the same codex. Clearly, this was not an act designed to increase efficiency through the division of labour - for any of them could easily have completed an entire booklet alone. It seems that in addition to being personally involved in the project, it was also important that the participants produced a single object together to make the offering as a group. The booklet was a physi- 
cal token of this act, signifying its collective nature. This kind of group offering is parallel to the situation seen in votive silk paintings from Dunhuang, which sometimes depict entire families of donors. ${ }^{130}$ Although there are always one or two main donors called shizhu 施主 (dānapati), by being visually present in the picture, the other family members also actively-and personally-participate in making the offering. Similarly, votive stelae may also record hundreds of contributors.

\subsection{Manuscripts P.3932 and P.3136}

Although S.5531 appears to be an ad hoc compilation, there are a number of comparable items in the Dunhuang corpus. One of the more similar ones is P.3932 from the Pelliot collection, a small codex already mentioned above as an example of a manuscript that opens with a drawing of the donors. It is $12 \times 7.4$ $\mathrm{cm}$ in size, similar to the dimensions of S.5531 (i.e. $12.5 \times 7.3 \mathrm{~cm}$ ). Naturally, the identical book form and similar size suggest a connection between the two items. This manuscript, however, has a maroon damask wrapping over its multi-layered front and back covers. The damask is worn at the edges but otherwise appears to be of good quality (Fig. 16). ${ }^{131}$ The photos show that the wear is heavier along the spine (i.e. the right side of the front and the left side of the back cover). The presence of the cover indicates that the codex was more than just a random collection of scriptures and was designed to last. It may still have been used for apotropaic purposes, with the care invested in producing a damask cover simply reflecting personal taste.

130 On donor families in the paintings, see Sørensen 2020a, 13-19.

131 I am grateful to Nathalie Monnet of the Bibliothèque nationale de France for verifying that the binding of P.3932 visible in the digital images is the original binding. 

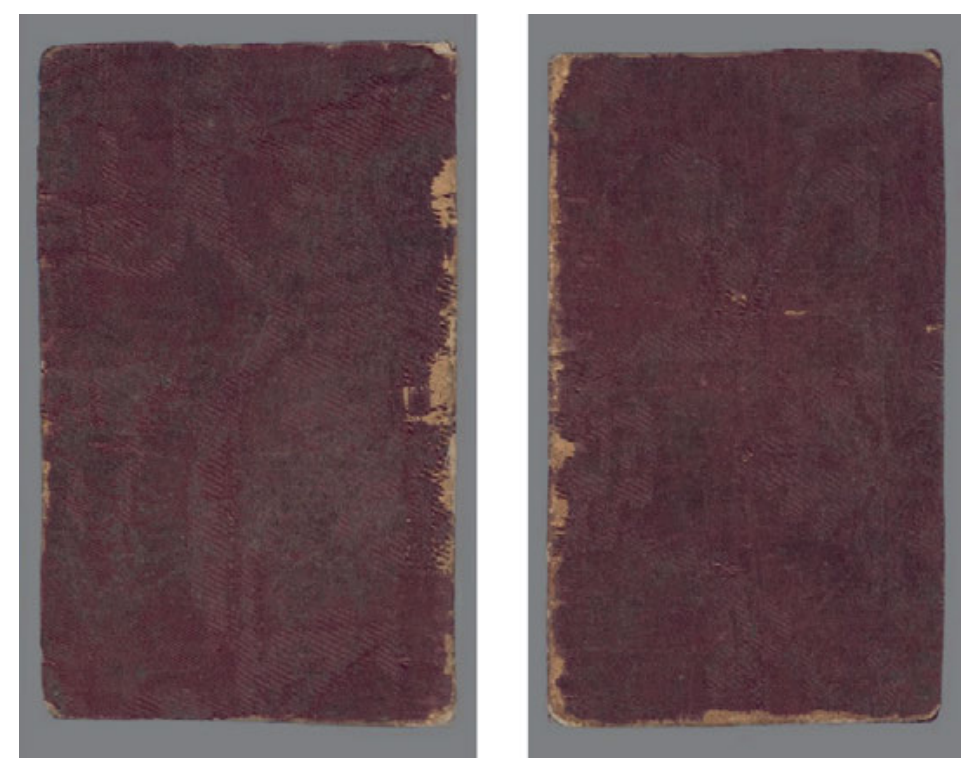

Fig. 16: The front (left) and back (right) cover of P.3932. $(12 \times 7.4 \mathrm{~cm}$; Bibliothèque nationale de France)

Fortunately, this manuscript is complete and thus the amount of missing text is not an issue. It comprises a total of 92 pages (i.e. 46 folia) in 23 bifolia, not counting the stiffer front and back covers which, unlike in most other Chinese codices from Dunhuang, are not part of the quire structure. The booklet consists of six quires, each with four bifolia. ${ }^{132}$ The bifolia are sewn together through six sewing holes with red and white threads, which still hold the leaves together securely. Consistent ruling lines are present from the first page to the last, dividing each page into four vertical columns with $0.5-0.8 \mathrm{~cm}$ margins at the top and bottom. This layout is similar to that of manuscript S.5531 above, although the side margins are narrower (ca. $0.2-0.3 \mathrm{~cm}$ ).

Turning to the next page, we find a two-page line drawing of Bodhisattva Guanyin with two donors kneeling in front of him on a mat (see Fig. 7 above). Roughly contemporary scenes depicting donors in the act of worship (gongyang) are common in silk paintings. Appearing at the beginning of the codex suggests that this couple is making an offering through the production of the manuscript.

132 For a description of the manuscript, including its codicological features, see Soymie et al. 1991, 423-424. 
The pictures of the bodhisattva and the donors have been executed with considerable skill, suggesting the involvement of a trained artist.

The first text starting immediately after the picture is the Guanyin jing, as was the case in codex S.5531. As the book is complete, the head title is present, and is the standard one for the text: Miaofa lianhua jing Guanshiyin pusa Pumen pin di nianwu 妙法蓮華經觀世音菩薩普門品第廿五 (Sutra of the Lotus of the Wonderful Dharma, Chapter 25: The Universal Gateway of Bodhisattva Guanshiyin). The end title reads Guanyin jing yi juan 觀音經一卷 (Scripture of Guanyin, in one juan). The text takes up about two-thirds of the whole book and is written in a skilled and confident hand, possibly a hired one. We have no information on this individual, he could have been a scribe, monk or just someone with good handwriting offering his services for payment. The donors, in turn, would have accrued karmic merits through the act of paying for the production of the manuscript. Yet the hand could equally have been that of someone in the family, possibly even the main donor.

The codex continues with the Heart sutra and several additional texts, as was the case in S.5531. In fact, the first five of the total seven texts in P.3932 overlap with the contents of S.5531, a pattern that warrants closer comparison. ${ }^{133}$ The seven texts in P.3932 are as follows:

1. Miaofa lianhua jing Guanshiyin pusa pumen pin di nianwu 妙法蓮華經觀世 音菩薩普門品第廿五 (Sutra of the Lotus of the Wonderful Dharma, Chapter 25: The universal gateway of Bodhisattva Guanshiyin)

2. Bore boluomiduo xin jing 般若波羅蜜多心經 (Prajñāpāramitā-hṛdaya-sūtra)

3. Foshuo xuming jing 佛說續命經 (Sutra Spoken by the Buddha on Extending Life)

4. Foshuo Dizang pusa jing 佛說地藏菩薩經 (Sutra Spoken by the Buddha on Bodhisattva Kșitigarbha)

5. Foshuo jie baisheng yuanjia tuoni jing 佛說解百生怨家陀尼經 (Sutra Spoken by the Buddha on the Dhāraṇi for Dispelling Resentment Accumulated in the Course of a Hundred Lifetimes) ${ }^{134}$

6. Cishi zhenyan 慈氏眞言 (Mantra of Maitreya)

7. Jing kouye zhenyan 浄口業眞言 (Mantra for the Purification of Karma Caused by Speaking).

133 Cf. Kuo 2000, 694.

134 This title omits the second syllable of the word tuoluoni 陀羅尼 (dhāranīi). 
Compared with S.5531, the sequence of texts is different, possibly because there was a certain degree of flexibility with regards to which texts, and in what order, should be part of such a manuscript. It is apparent that the two manuscripts are analogous not only in their physical form and size but also their content, which inevitably points to a connection in function and use. Indeed, most multiple-text manuscripts of this type contain various combinations of the same few short texts. ${ }^{135}$

Text No. 6 is a mantra entitled Cishi zhenyan 慈氏眞言 (Mantra of Maitreya). This also occurs in manuscript S.5555 (a similar type of codex) at the end of the Guan Mile pusa shangsheng Doushuaituo tian jing 觀彌勒菩薩上生兒率陀天經 (T.452.14; Sutra on the Visualisation of the Bodhisattva Maitreya's Rebirth in Tușita Heaven). ${ }^{136}$ The Cishi zhenyan features at the end of the same scripture in several printed books from Khara-khoto, confirming its popularity in the Tangut state two centuries later. ${ }^{137}$ In fact, an imperial colophon at the end of the printed scriptures mentions the distribution of a hundred thousand copies of the Guan Mile pusa shangsheng Doushuaituo tian jing in Chinese and Tangut. ${ }^{138}$ As the surviving exemplars reveal, copies of the scripture from the Tangut state invariably included the Cishi zhenyan mantra. In this manuscript, however, the Cishi zhenyan is on its own, without the scripture, and is followed by a note saying that if one recites the mantra three hundred thousand times, one will be born in Tușita Heaven and can see Maitreya in person. Following this comes the Jing kouye zhenyan 浄口業眞言 (Mantra for the Purification of Karma Caused by Speaking), a short mantra of merely fourteen characters, a common element in manuscripts of the Diamond sutra but also a variety of other scriptures. ${ }^{139}$ Fig. 17

135 Teiser 1994, 273-274 and Kuo 2000, 694-695.

136 Nearly three decades ago Wang Juan 1992, 227 noted that S.5555 was the only manuscript where this mantra survived. But it is now known that other specimens of the mantra, both printed and handwritten, exist. It is probably relevant that manuscript $\mathrm{S} .5555$ also includes the Foshuo yan shouming jing.

137 See the series of concertinas dated to 1189 in Lev N. Menshikov's catalogue of the Chinese material from Khara-khoto (i.e. the Kozlov collection) in what is known today as the Institute of Oriental Manuscripts (Men'shikov 1984, 194-201). As far as I can see, the mantra appears in items TK-58, TK-59, TK-60, TK-81, TK-82, TK-83 and TK-85.

138 For a partial translation of the imperial colophon, see Dunnell 1996, 225.

139 See, for example, manuscripts S.1846 and P.3325, or the famous printed copy of the Diamond sutra from 868 , celebrated as the earliest complete specimen of a dated printed book in the world (Or.8210/P.2). The mantra served, as suggested to me by Henrik Sørensen, as a 'spiritual toothbrushing' before the recitation starts. It remained extremely popular in later centuries; for example, in the novel Journey to the West (Xiyou ji 西遊記, Chapter 13) Sanzang 三藏 recites it before chanting the scriptures; see Xue Keqiao 1994, 50. 
shows these two mantras together on the last three inscribed pages of our codex. The white arrows mark the beginning of each text. Visually, the mantras form a single block of text that bear no resemblance to the rest of the manuscript. Within this block, however, the boundaries are much less obvious.

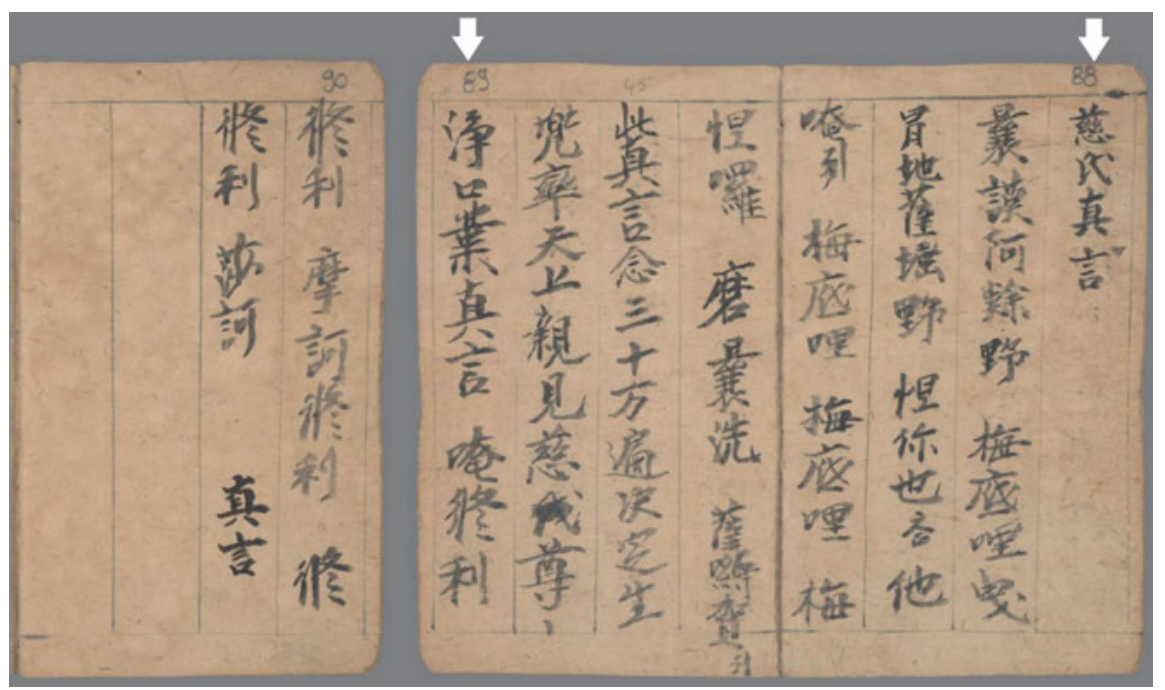

Fig. 17: The two mantras at the end of manuscript P.3932 (from right to left).

The mantras constitute the only text in this booklet which does not also occur in manuscript S.5531. ${ }^{140}$ They are written in the same inept hand, in contrast with the total of 83 pages written by two far more practised hands. In terms of the quality of handwriting, the first three scriptures are in a highly competent hand. Texts 4 and 5 seem to be in a different but still fairly practised hand and, finally, the two short mantras at the end in a third, unskilled hand. ${ }^{141}$ The amount of text these three hands (A, B and C) copied is also interesting. Using the pages as units of measure, we find the following distribution: ${ }^{142}$

140 This shows that although the mantras often accompanied particular scriptures (i.e. Diamond sutra), they could also function on their own as independent texts.

141 Zhang Zong 2001, 95 agrees that the first three scriptures in P.3932 are in one hand and the following two in another. The short mantras at the very end are obviously in a third.

142 For counting the pages, I rely on the page numbers added in pencil by modern conservators. The drawings are on pages $2-3$, and the text begins on page 4 . 


\begin{tabular}{llll}
\hline Hand A: pp. 4-75 & 71 pages & $82.5 \%$ & competent \\
Hand B: pp. $76-87$ & 12 pages & $14 \%$ & competent \\
Hand C: pp. $88-90$ & 3 pages & $3.5 \%$ & incompetent \\
\hline
\end{tabular}

We can see that $\mathrm{C}$, the incompetent hand, only wrote three pages-merely $3.5 \%$ of the total text in the codex. Clearly, it was important to include this person in the codex, albeit with a minimal amount of text. The mantras were possibly written by one of the two donors whose image appears at the beginning of the manuscript. As the male donor's headwear verifies he was an official and therefore must have possessed reasonably good writing skills, it may have been the wife who wrote them. The husband was probably hand B, writing texts Nos. 4 and 5, whereas the first three texts in the best hand were entrusted to a hired hand (i.e. A). Although theoretically it is possible that hand A belonged to a third individual, someone from the same family, several details point to the involvement of an outside person.

First, the codex has a damask cover and is professionally bound, which could not have been done as part of a do-it-yourself project. Second, the pictures of the donors and the bodhisattva betray specialised skills. Third, the picture shows only two donors, which suggests that the third hand was not from within the family. Finally, the fact that hand A copied over $80 \%$ of the booklet in highly competent handwriting is an indication that his status was quite different from the other two hands. If anyone, A is more likely to be the outside person, copying texts on behalf of the donors. Hands B and C wrote a total of 15 pages, comprising less than a fifth of the entire manuscript. Adding two texts, no matter how short, in their own hand must have ensured the religious efficacy of the manuscript and was the final step in helping take possession of the merits generated by the copying of all of the texts.

The damask cover of the codex is relatively unusual, and it is precisely for this reason that we can link it with manuscript P.3136, another codex covered in silk cloth of similar colour. The cover of P.3136, however, is independent of the body of the manuscript, and wraps around it in a manner similar to modern dust jackets. The outside cover and the individual bifolia are sewn together using a simple overcast stitch. Additional sewing holes are visible near the stitching holes (Fig. 18), which intimate that the current binding is not the original binding. Instead, the crudeness of the stitching suggests that this was a quick fix to stabilise the booklet after it had come apart. Similar to a modern dust jacket, the front cover has a flap ( $4.5 \mathrm{~cm}$ wide), possibly to strengthen the edge of the fabric and to prevent wear. 


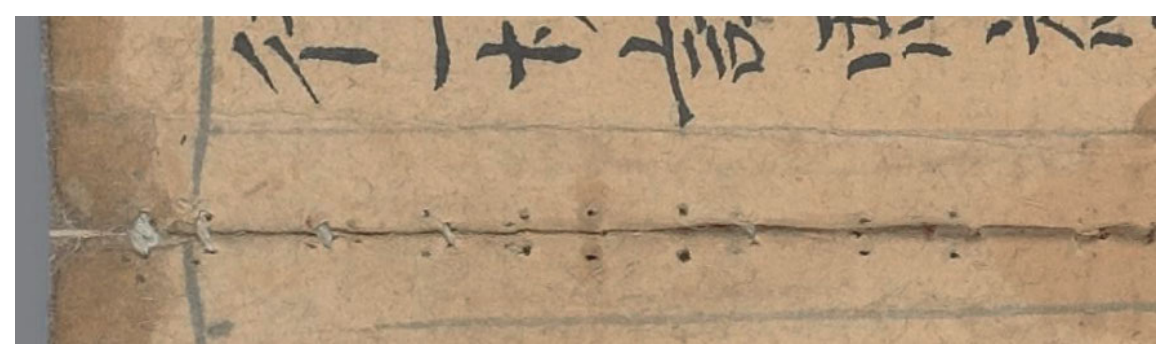

Fig. 18: Unused sewing holes along the stitching in manuscript P. $3136 .(16.5 \times 11.5 \mathrm{~cm}$; Bibliothèque nationale de France)

In terms of its physical structure, the manuscript consists of four bifolia and a singleton (i.e. stand-alone folio) at the very beginning of the codex. One side of the singleton is empty but the other has a painting of a red Guanyin enhanced with gold (Fig. 19). ${ }^{143}$ Athough the painting is damaged, the attention to detail and the use of gold are in sharp contrast to the improvised manner of the stitching. The painting is on a separate leaf with unclear physical boundaries, thus it is not impossible that it originated from elsewhere and was incorporated into the new structure by the person who rebound the codex. Opposite the image are eight lines from the Fomu jing 佛母經 (Sutra of the Buddha's Mother; T.2919.85). The beginning of the text is missing, suggesting that the physical manuscript in its current form is also incomplete.

143 Drège 1999a, 110. Thanks to Sam van Schaik, who pointed out to me that red Avalokiteśvara is a meditation deity appearing in some of the Tibetan tantric texts from Dunhuang; cf. van Schaik 2006, 62. 


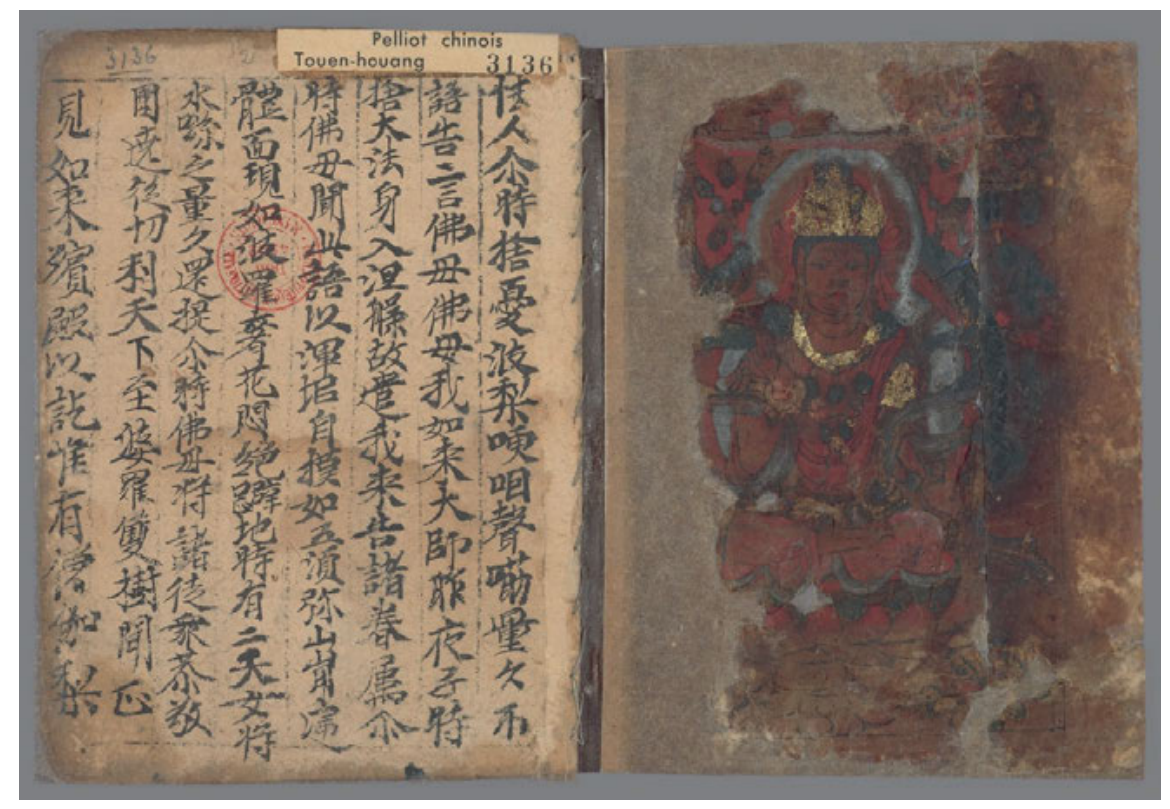

Fig. 19: The beginning of manuscript P.3136. $(16.5 \times 11.5 \mathrm{~cm}$; Bibliothèque nationale de France $)$

Indeed, a now missing bifolio must have been glued before the page with the Fomu jing, as can be seen from the ripped surface of the paper along the right edge of the page (Fig. 19). On the image here, the surface with the rip damage is lighter in colour. There are similar traces at the centre of every second opening, which reveals that originally this was a glued codex. ${ }^{144}$ At one point someone had taken the glued bifolia apart, damaging the paper along the edges in the process. Then someone, perhaps the same individual, stitched the leaves together (on two separate occasions), along with the cover and possibly the painting. This secured the physical structure of the manuscript and ensured no additional leaves were lost.

With its four and a half bifolia, this is a much slimmer codex than any of the previous ones. Accordingly, it only contains only three texts, all of which are very short. The three texts are as follows:

144 The reason why the tear is at the centre of every second page spread is that the other spreads represent the centrefolds of the bifolia and thus were not glued. 
1. Fomu jing 佛母經 (Sutra of the Buddha's Mother)

2. Bore boluomiduo xin jing 般若波羅蜜多心經 (Prajñāpāramitā-hṛdaya-sūtra)

3. Molizhitian jing 摩利支天經 (Sutra of Marīci-deva) $)^{145}$

The Fomu jing is a short apocryphal sutra of about 500 characters. It survives in 49 copies in Dunhuang and another five fragments from Turfan, representing several textual versions. ${ }^{146}$ In our manuscript, only one page of the Fomu jing is present, with about 180 characters (along with the title) from the beginning missing, which estimating from the 125 characters on the existing page, would amount to a page and a half. The missing text from the beginning is the result of one or more bifolia having been removed, but it is unclear why the text breaks off at the end of the page. Instead of continuing with the Fomu jing, the next page (i.e. the verso side of the same folio) contains the Heart sutra, written in a completely different hand. Apparently, the individual copying the Fomu jing stopped at the end of the page without finishing the text. The other two texts in the manuscript are written in the same hand and overlap with the content of the codices discussed above, which is yet another piece of evidence linking this manuscript to other items in our group of multiple-text manuscripts.

145 This is actually the Foshuo Molizhitian pusa tuoluoni jing 佛說摩利支天菩薩陀羅尼經 (T1255a, 21), rather than the Foshuo Molizhitian jing 佛說摩利支天經 (T1225b, 21), as the title would suggest.

146 On the Fomu jing, see Durt 1996, Nishiwaki 2006, Nishiwaki 2007, Lin Renyu 2012, Kishida 2014 and Zhang Xiaoyan 2016, 76. The Taishō version of the text is based on the incomplete text in S.2084. 


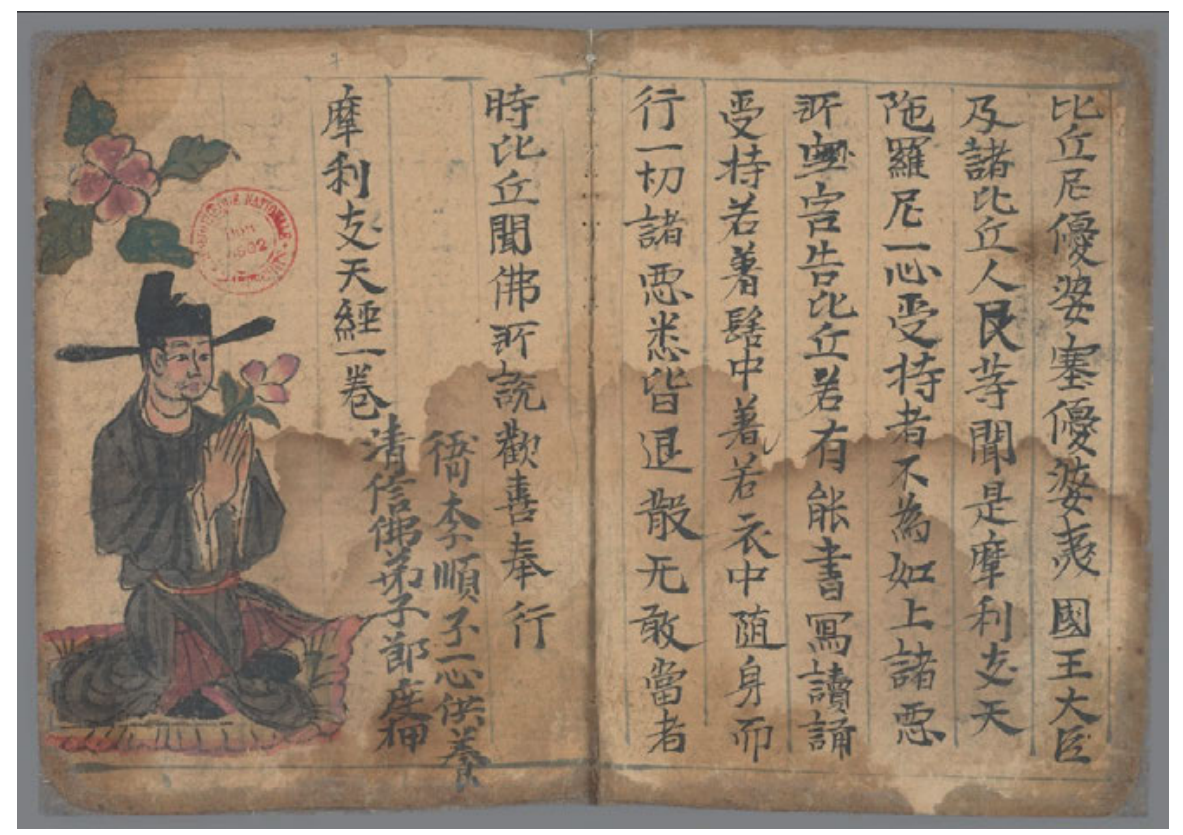

Fig. 20: Donor's image and colophon in manuscript P.3136. $(16.5 \times 11.5 \mathrm{~cm}$; Bibliothèque nationale de France)

Just as importantly, at the end of the last text we find a painted image of a male donor kneeling on a mat and worshipping with two palms put together (Fig. 20). He is holding a flower between his palms, and a similar kind of flower appears above him, in the top left corner of the page. ${ }^{147}$ This painting is similar in quality to the drawings seen in other codices but differs from the more elaborate image of Guanyin on the singleton at the beginning of this booklet. Unlike in the other examples, the donor is facing not Guanyin but the end of the Molizhitian jing. Nonetheless, as, the beginning of the manuscript features a painting of Guanyin, the donor and the bodhisattva form a frame around the three texts between them. Directly in front of the figure of the donor is a colophon stating his name and that this manuscript constitutes an offering:

\section{清信佛弟子節度押衙李順子一心供養}

Wholeheartedly offered by the jiedu yaya Li Shunzi, the Buddha's disciple of pure faith.

147 A full-page painting of possibly the same type of flower appears two pages later in the manuscript. 
The colophon is written from left to right, in the opposite direction to how Chinese is normally written. ${ }^{148}$ There is no date but the direction of writing and the codex form indicate the tenth century. The title jiedu yaya 節度押衙, designating an officer subordinate to the military commissioner, is also closely connected to the Guiyijun regime. ${ }^{149}$ The donor's handwriting in the colophon is different from either of the two hands that copied the three texts in the booklet. This can be seen in the execution of particular strokes, as the hand in the colophon tends to write some strokes thicker, as opposed to the more consistent thickness of strokes in the three scriptures. The three short texts in this manuscript typically occur towards the end of other codices, which begin with the much longer Guanyin jing. This implies that P.3136 is only the end of the codex, most of which had been lost before someone bound the remaining pages together using the impromptu stitching.

\subsection{Other examples: S.5618 and beyond}

Above, we have examined several multiple-text manuscripts in a codex form. There are, however, also concertinas with similar content and structure. One such example is S.5618, an undated manuscript with no colophon. Its dimensions are $12.5 \times 6.3 \mathrm{~cm}$, which are similar to those of the two codices examined above (i.e. S.5531 and P.3932), both of which are approximately $12 \times 7.3 \mathrm{~cm}$ in size. The pages in S.5618, however, are slightly taller and narrower, resembling more the shape of pothi leaves. ${ }^{150}$ This is also the case with most Tibetan concertinas from Dunhuang, and therefore the majority of concertina manuscripts in general. Fig. 21 shows two adjacent pages with the end of one text and the beginning of another.

\footnotetext{
148 For this phenomenon in the manuscripts, see Chapter Three in this book.

149 In the Stein collection, the dated manuscripts mentioning this title are S.4363 (dated 942) and S.2973 (dated 970). For a study of the title in Dunhuang, see Zhao Zhen 2001.

150 These dimensions were not a local phenomenon but were extremely popular in other parts of East Asia. Many of the Tangut manuscripts and imprints from Khara-khoto, from approximately two centuries later, are concertinas of similar size. In fact, to this day, concertinas of this shape remain a common form of short Buddhist scriptures in East Asia.
} 


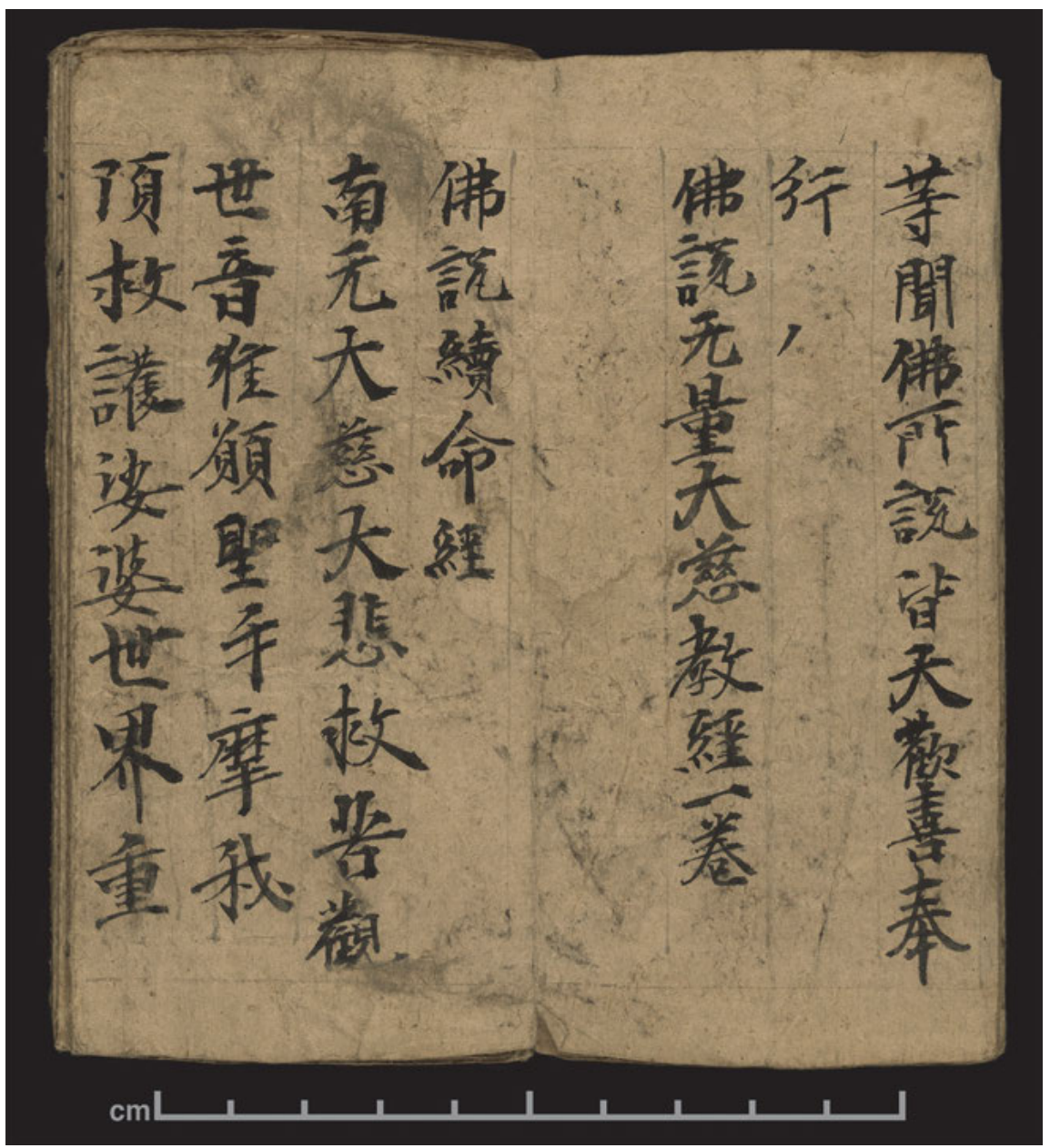

Fig. 21: Two pages from concertina S.5618. $(12.5 \times 6.3 \mathrm{~cm}$; The British Library $)$

The manuscript has no proper cover, except for an empty folio at the very end. It is slightly narrower than a proper page and thus acts as a flap covering the back. Physically, the manuscript consists of 6 sheets of paper glued together into a long, scroll-like writing surface, which is then folded into 38 folia. The size of the paper sheets is $13.3 \mathrm{~cm}, 49 \mathrm{~cm}, 31.4 \mathrm{~cm}, 45.4 \mathrm{~cm}, 48.5 \mathrm{~cm}$ and $48.8 \mathrm{~cm}$, showing that a full size sheet was $48.5-50 \mathrm{~cm}$ in length. ${ }^{151}$ The seamlines are consistently located

151 Special thanks to Mélodie Doumy for kindly measuring the sheet sizes in this manuscript. 
0.5-1 $\mathrm{cm}$ before or after the folds. The top and bottom edges of the pages are slightly arched; a feature also seen in codices and pothis. The arched edges create a contrast with the straight horizontal lines of top and bottom margins.

The manuscript contains four short Buddhist texts, which show a significant degree of overlap with the multiple-text codices discussed so far. Using the titles seen in the manuscript, the four texts are as follows: $:^{152}$

1. Foshuo wuliang dacijiao jing 佛說無量大慈教經 (Sutra Spoken by the Buddha on the Teaching of the Immeasurable Great Compassion)

2. Foshuo xuming jing 佛說續命經 (Sutra Spoken by the Buddha on Prolonging Life)

3. Foshuo Dizang pusa jing 佛說地藏菩薩經 (Sutra Spoken by the Buddha on Bodhisattva Kșitigarbha)

4. [Foshuo Molizhitian tuoluoni zhou jing 佛説摩利支天陀羅尼呪經] (Dhāraṇi Sutra Spoken by the Buddha on Marīci-deva)

The Foshuo wuliang dacijiao jing 佛說無量大慈教經 is an apocryphal scripture that survives in Dunhuang in over forty manuscripts, of which seven have the complete text. ${ }^{153}$ The Taishō edition (T2903, 85) is based on S.1627, which only contains about a third of the full text. The version in our concertina is missing about 150 characters from the beginning and shows a number of discrepancies with other Dunhuang witnesses, such as manuscript S.6961.

Once again, the manuscript features a seemingly haphazard collection of scriptures (some of them apocryphal) in a concertina form, yet the repeated occurrence of this pattern in a series of manuscripts proves that such compilations were neither unusual nor random. Instead, we can see that such multiple-text booklets formed a distinct group of manuscripts with shared physical characteristics and textual content. Taking manuscript S.5618 as a representative example, we can use the four scriptures it contains to locate other manuscripts that may potentially belong to the same group. Tracing the distribution of the four texts across the Dunhuang corpus allows us to identify manuscripts which contain more than one such text. Based on the concordance of Buddhist texts in Dunhuang manuscripts compiled by the International College for Postgraduate Buddhist Studies Library, Table 3 displays the manuscripts in which the four texts occur. ${ }^{154}$

152 The square brackets are to indicate the title of the fourth text does not appear in the manuscript. 153 Zhang Xiaoyan 2016, 69. The seven manuscripts are S.110, S.6961, BD00943, BD14125, BD05242, Dunbo-56 and Hane-203.

154 Kokusai bukkyōgaku daigakuin daigaku fuzoku toshokan 2015. Despite the great utility of this concordance, it is not complete. It lists, for example, only 34 manuscripts with the Wuliang 
Tab. 3: Distribution of the four apocryphal scriptures in S.5618 across the Dunhuang corpus.

\begin{tabular}{|c|c|c|}
\hline Title & Quantity & Pressmarks \\
\hline $\begin{array}{l}\text { Foshuo wuliang } \\
\text { dacijiao jing } \\
\text { 佛說無量大慈教經 }\end{array}$ & 34 & $\begin{array}{l}\text { BD00933, BD00943, BD03731, BD05242, BD06380, } \\
\text { BD06464, BD07807, BD09235, BD09236, BD09592, } \\
\text { BD09862, BD10962, BD12274, BD13797, BD14125, } \\
\text { Dunbo-56, F-350, Ax-1588, Ax-2723, Ax-5465, Gantu-16, } \\
\text { Hane-164, Hane-203, Hane-467, S.110, S.1018, S.1627, } \\
\text { S.1726, S.4368, S.4559, S.5618, S.6961, S.7006, } \\
\text { S.7156 }\end{array}$ \\
\hline $\begin{array}{l}\text { Foshuo xuming jing } \\
\text { 佛說續命經 }\end{array}$ & 18 & $\begin{array}{l}\text { BD00693, Дx-883, Дx-927, Дx-1009, Дx-1591, Ganbo-16, } \\
\text { Hane-412, P.2374, P.3115, P.3760, P.3932, S.1215, } \\
\text { S.3795, S.5531, S.5535, S.5581, S.5618, S.5679 }\end{array}$ \\
\hline $\begin{array}{l}\text { Foshuo Dizang pusa } \\
\text { jing } \\
\text { 佛說地藏菩薩經 }\end{array}$ & 26 & $\begin{array}{l}\text { BD00919, BD03862, BD03925, BD07281, BD09147, } \\
\text { Дx-277, Дx-397, Дx-2636, Дx-3000, Ganbo-16, P.2289, } \\
\text { P.3748, P.3760, P.3932, S.431, S.2247, S.5458, } \\
\text { S.5531, S.5535, S.5618, S.5672, S.5677, S.6257, } \\
\text { S.6983, Shangbo-48, Shangtu-62 }\end{array}$ \\
\hline $\begin{array}{l}\text { Foshuo Molizhitian } \\
\text { tuoluoni zhou jing } \\
\text { 佛説摩利支天陀羅 } \\
\text { 尼呪經 }\end{array}$ & 13 & $\begin{array}{l}\text { Дx-213, Дx-927, Hane-299, Hane-508, P.3110, P.3136, } \\
\text { P.3759, P.3824, P.3912, S.5391, S.5392, S.5531, } \\
\text { S.5618 }\end{array}$ \\
\hline
\end{tabular}

Looking at the list in the table, we have to remember that the texts may have different versions, some longer, others shorter, and their differences would not necessarily be reflected in the titles. Nevertheless, my intention here is not so much to trace specific versions or lineages of texts as to identify manuscripts with similar content. What is of interest here is which manuscripts in the table contain more than one of these four scriptures. Some may feature combinations with other scriptures but, for the sake of the current exercise, the investigation is limited to those involving two or more of the four texts found in manuscript S.5618 (i.e. in Table 3). The one item that contains all four texts is S.5618, which is not surprising, as it is the concertina we used as the starting point of the search. The other relevant manuscripts are as follows:

dacijiao jing, including the so-called 'small format' version, whereas Zhang Xiaoyan 2016 records 44 items (but curiously omits F-350, which is in the concordance). 


\begin{tabular}{|c|c|}
\hline$-\quad \mathrm{S} .5531$ & Foshuo xuming jing 佛說續命經 \\
\hline & Foshuo Dizang pusa jing 佛說地藏菩薩經 \\
\hline & Foshuo Molizhitian tuoluoni zhou jing 佛説摩利支天陀羅尼呪經 \\
\hline P.3932 & Foshuo xuming jing 佛說續命經 \\
\hline & Foshuo Dizang pusa jing 佛說地藏菩薩經 \\
\hline Дх-927 & Foshuo xuming jing 佛說續命經 \\
\hline & Foshuo Molizhitian tuoluoni zhou jing 佛説摩利支天陀羅尼呪經 \\
\hline Ganbo-16 & Foshuo xuming jing 佛說續命經 \\
\hline & Foshuo Dizang pusa jing 佛說地藏菩薩經 \\
\hline S.5535 & Foshuo xuming jing 佛說續命經 \\
\hline & Foshuo Dizang pusa jing 佛說地藏菩薩經 \\
\hline P.3760 & Foshuo xuming jing 佛說續命經 \\
\hline & Foshuo Dizang pusa jing 佛 \\
\hline
\end{tabular}

The presence of the Foshuo xuming jing in all eligible manuscripts forms a conspicuous pattern. Similarly, all but one of the manuscripts include both the Foshuo xuming jing and the Foshuo Dizang pusa jing. Undoubtedly, these were among the most popular texts in such multiple-text manuscripts. We can also see is that this group contains two codices already examined earlier in this chapter (i.e. S.5531 and P.3932). Aside from these, the remaining manuscripts are Дx-927, Ganbo-16, S.5535 and P.3760.

Of these, Дx-927 is yet another small codex of 16 folia $(14 \times 10 \mathrm{~cm})$ containing several short texts, including incantations and the Heart sutra. This is obviously a similar booklet to those discussed earlier and should be treated as part of the same group. In his catalogue of Chinese manuscripts from Dunhuang in the Oldenburg collection in St. Petersburg (then Leningrad), Lev N. Menshikov divides the contents of the booklet into eight entries, with somewhat subjective results, as some of the writings do not amount to proper texts. ${ }^{155}$ This is especially true for the scribble-like notes a few pages into the booklet, which record, in an untrained hand, a number of names and titles in no apparent order.

Ganbo-16 from the collection of the Gansu Provincial Museum is yet another similar codex with a series of shorter texts. The first is the Quanshan jing 勸善經 (Scripture Urging Kindness; T.2916, 85), which ends with a colophon dating to the nineteenth day of the Zhenyuan 貞元 reign (803). ${ }^{156}$ The codex form, however,

155 Men'shikov et al. 1963, 315.

156 For a translation of the Quanshan jing into English, see Goble 2017. See also Yuankong 1992, Zhang and Zhang 2009, Gen 2012 and Zhang Xiaoyan 2015. 
only appeared in Dunhuang at the end of the ninth century and thus the year 803 cannot denote the time when this particular manuscript was written, especially as colophons with the same date appear in quite a few manuscripts with the Quanshan jing. ${ }^{157}$ In manuscript P.3036, for example, a second colophon follows the 803 one, attributing the copying to a certain Baoxuan 寶宣 in the third year of the Tianfu 天福 reign (938), demonstrating the date 803 was copied along with the text. ${ }^{158}$ In Ganbo-16, the Quanshan jing is followed by the Foshuo Dizang pusa jing, Foshuo Molizhitian jing, Foshuo xuming jing, Foshuo Guanshiyin jing 佛說觀世音經, Foshuo rulai chengdao jing 佛說如來成道經 (Sutra Spoken by the Buddha on the Tathāgata Attaining the Way) and Foshuo daweide Chishengguang rulai jixiang tuoluoni jing 佛說大威德熾盛光如來吉祥陀 羅尼經 (Auspicious Great Dhāraṇi Sutra Spoken by the Buddha on Tejaprabhā Tathāgata). The title of the Foshuo yan shouming jing is also present but the text itself is not there. This is, once again, a similar collection of short scriptures, written in different hands and ending with an incantation.

S.5535 is a codex of 27 folia, $17 \times 11.3 \mathrm{~cm}$ in size, with a back cover made of paper and red fabric. ${ }^{159}$ The thread used for the binding has not survived but the remaining holes indicate that this was a sewn codex. Li Zhizhong regards the 'stab holes' in the side of the folia as evidence of it being an early 'threadbound' book, similar to those of the Song period. ${ }^{160}$ The holes, however, are probably traces of a secondary stitching similar to that in manuscript P.3136 with the gilded painting of Guanyin. At any rate, it is clear that before being deposited in the Dunhuang library cave, the booklet had already undergone some conservation work in an attempt to repair fire damage. Worms and rodents may have inflicted additional damage. The booklet begins with the Guanyin jing, followed by the Heart sutra, Foshuo xuming jing, Foshuo Dizang pusa jing and, finally, the Foshuo bayang shenzhou jing 佛說八陽神呪經 (Sutra on

157 A similar phenomenon is that of ninth and tenth century manuscripts containing examples of Wu Zetian 武則天 (r. 690-705) characters, which normally indicate the manuscript had been written during her reign. In such cases, however, it is evident that these idiosyncratic character forms were copied along with the text; see Drège 1984.

158 Ikeda 1990, 479 dates manuscripts of the Quanshan jing with a second colophon to the time of the second colophon but takes the date 803 at face value when there is only one colophon (ibid., 386). Similarly, Giles 1937, 24-25 dates manuscripts S.912 and S.1349 to 803, even though the date in the colophon cannot possibly refer to the time of copying.

159 Giles 1957, 84 claims that the fabric is silk but Li 1989, 115 identifies it as hemp cloth.

160 Ibid., and Li Zhizhong 1998, 323. 
the Miraculous Incantations of the Eight Yang). ${ }^{161}$ The manuscript features several different hands, none of which is particularly skilled or unskilled. The last pages have been left empty, perhaps to allow a donor to add another short scripture or a mantra. As mentioned above regarding Stein painting 209, the empty pages at the end of this codex are not an isolated case but a common phenomenon among the surviving multiple-text manuscripts. ${ }^{162}$

Finally, P.3760 is a tiny concertina with pages merely $6.5 \times 4.8 \mathrm{~cm}$ in size, about half the size of a credit card. The front and back are reinforced with a layer of colour paper, making the covers stiffer than usual (Fig. 22). Vertical ruling lines divide the front cover into three columns, the middle of which shows a crude drawing of an incense burner of the type commonly held by male donors in Dunhuang paintings. The right column contains the words Foshuo guan Mile pusa 佛說觀彌勒菩薩, using the ligature 茀 to write the word pusa 菩 薩 ('bodhisattva'). This appears to be an abbreviation of the title Foshuo guan Mile pusa shangsheng Doushuaituo tian jing 佛說觀彌勒菩薩上生兒率陀天經 (T452, 14), yet the text itself is not in the manuscript. The title is upside down in relation to the rest of the manuscript, confirming that it is not directly related to the content within.

161 This last text is only present as a stand-alone title, which makes it difficult to see which text it meant to represent. Most likely it would have been the Foshuo tiandi bayang shenzhou jing 佛說天地八陽神呪經 (T2897, 85), an apocryphal sutra allegedly translated by Yijing 義淨 (635-713), which is different from the Foshuo bayang shenzhou jing 佛說八陽神咒經 (T428, 14) translated by Dharmarakṣa (Zhu Fahu 笈法護, b. 233). The apocryphal sutra was very popular and survives in over a hundred manuscripts; see Gen 2008, 50-51. As manuscript evidence attests, the Chinese apocryphal text was also popular in Tibetan and Old Uighur translations. On the Tibetan translation, see Nishioka 1981, Stein 2010, 90-92 and 246-248, as well as Silk 2019, 238. The Old Uighur translation of the text has a vast secondary literature; see, for example, Haneda 1915, Yamada 1958, Ligeti 1971, Oda 2015 and, most recently, Li 2019. On a Tangut fragment, see Matsuzawa 2004.

162 Soymié et al. 1991, 250 notes that the colour is grey-blue, but it seems also to include a greenish undertone, perhaps the result of the discolouration of diluted ink. 


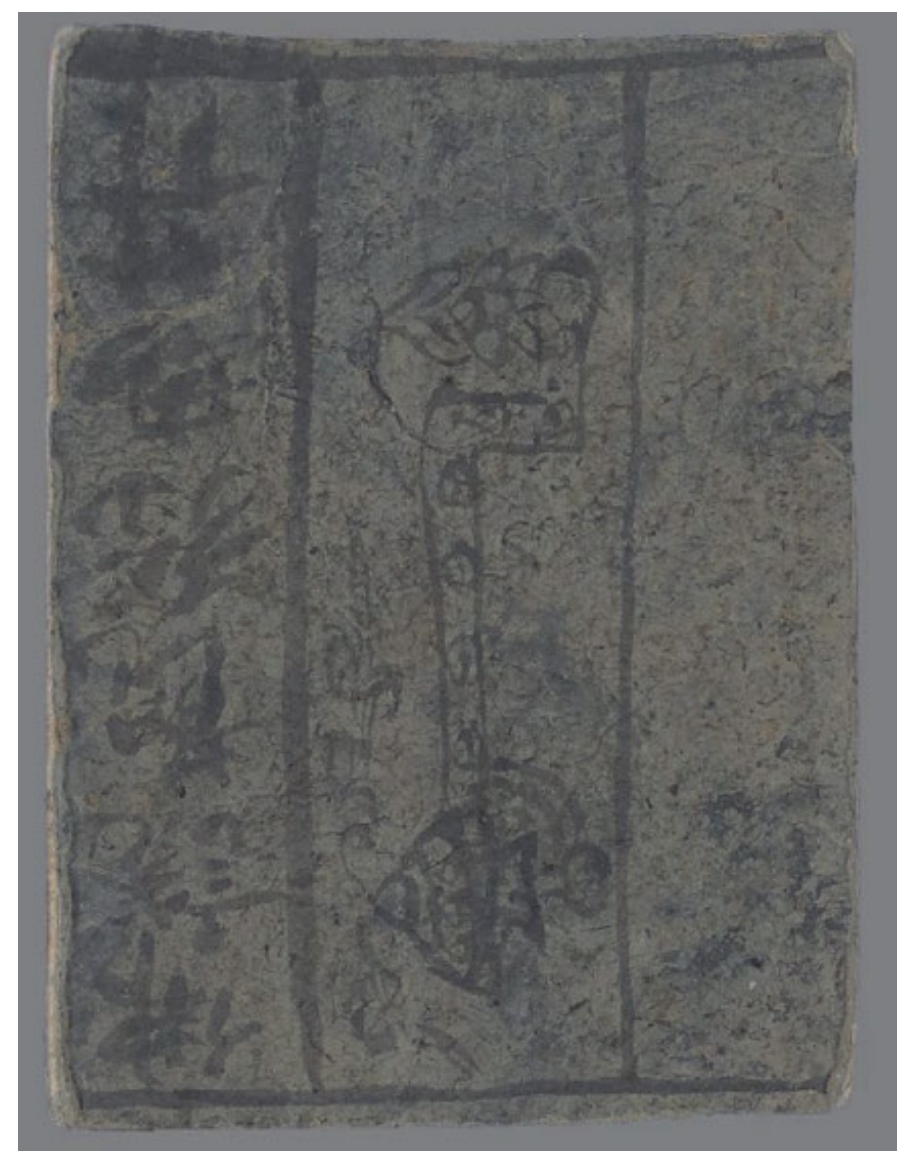

Fig. 22: The front cover of manuscript P.3760. $(6.5 \times 4.8 \mathrm{~cm}$; Bibliothèque nationale de France)

In terms of its form, this is a concertina consisting of a total of 115 pages, which modern conservators have numbered in pencil. Each page has four lines of text and most of the lines consist of six characters. The ruling is consistent and in red ink, in contrast with the black or grey ink commonly seen in manuscripts. The red ruling lines on some pages are extremely faint and hard to see in reproductions. It is possible to discern three different hands (A, B and C) in the manuscript, all of which are fairly unskilled. To demonstrate their peculiarities and differences, Fig. 23a-c shows three double pages with each of the three hands. 


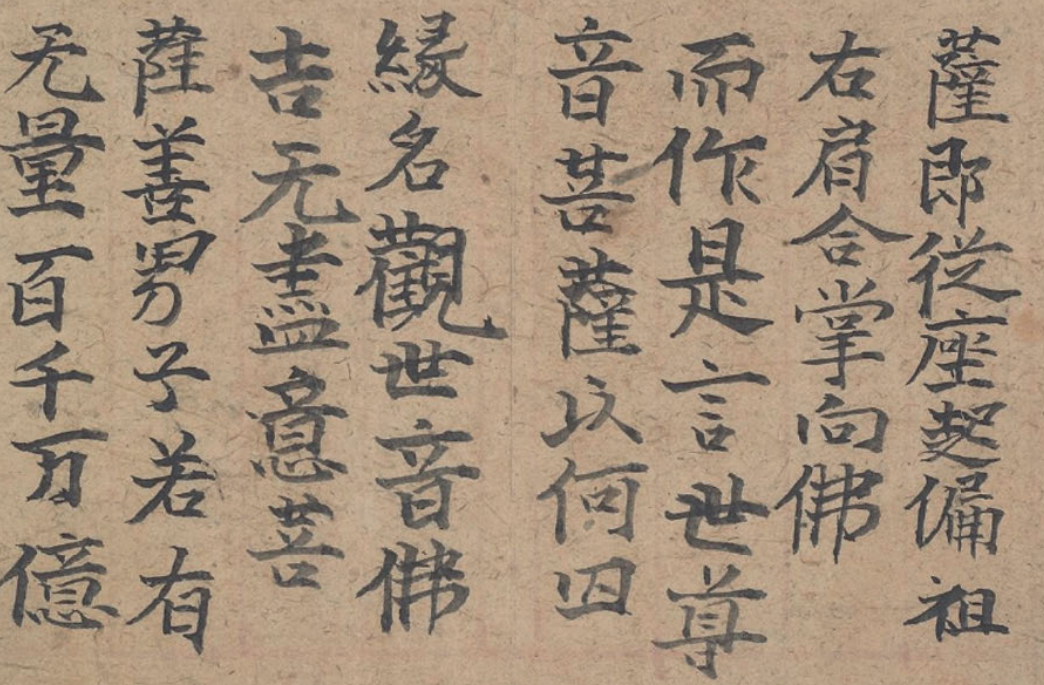

Fig. 23a: Hand A in manuscript P.3760.

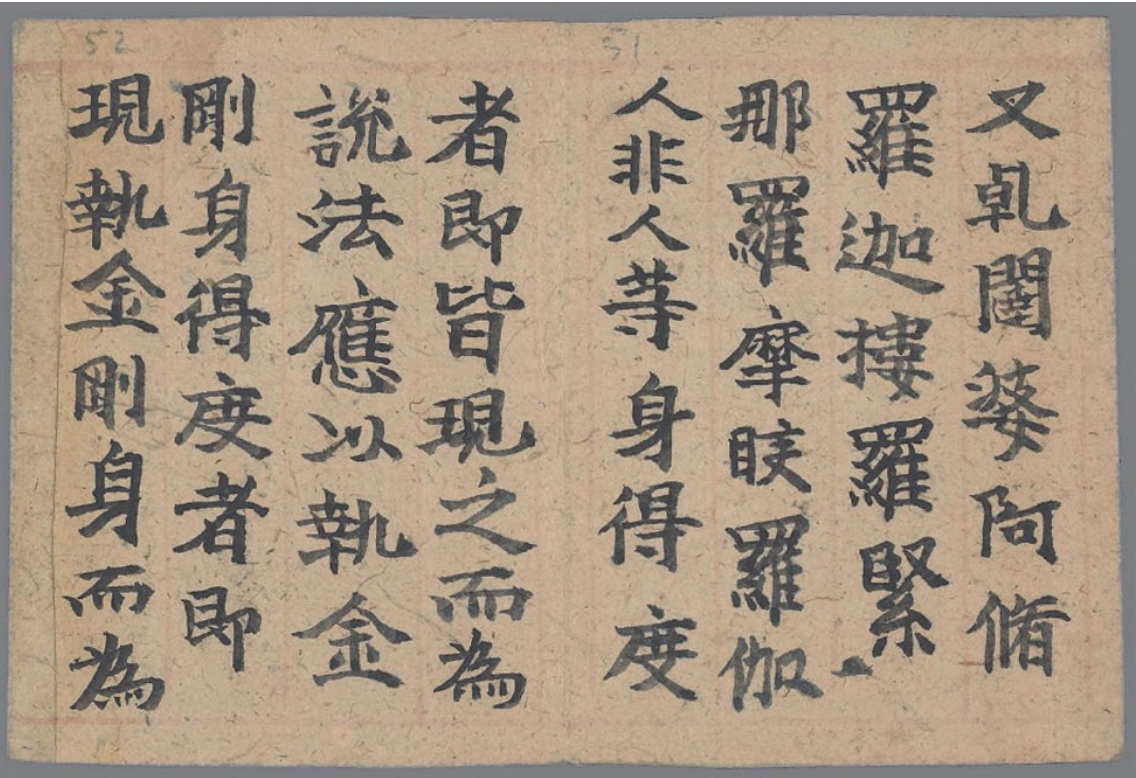

Fig. 23b: Hand B in manuscript P.3760. 


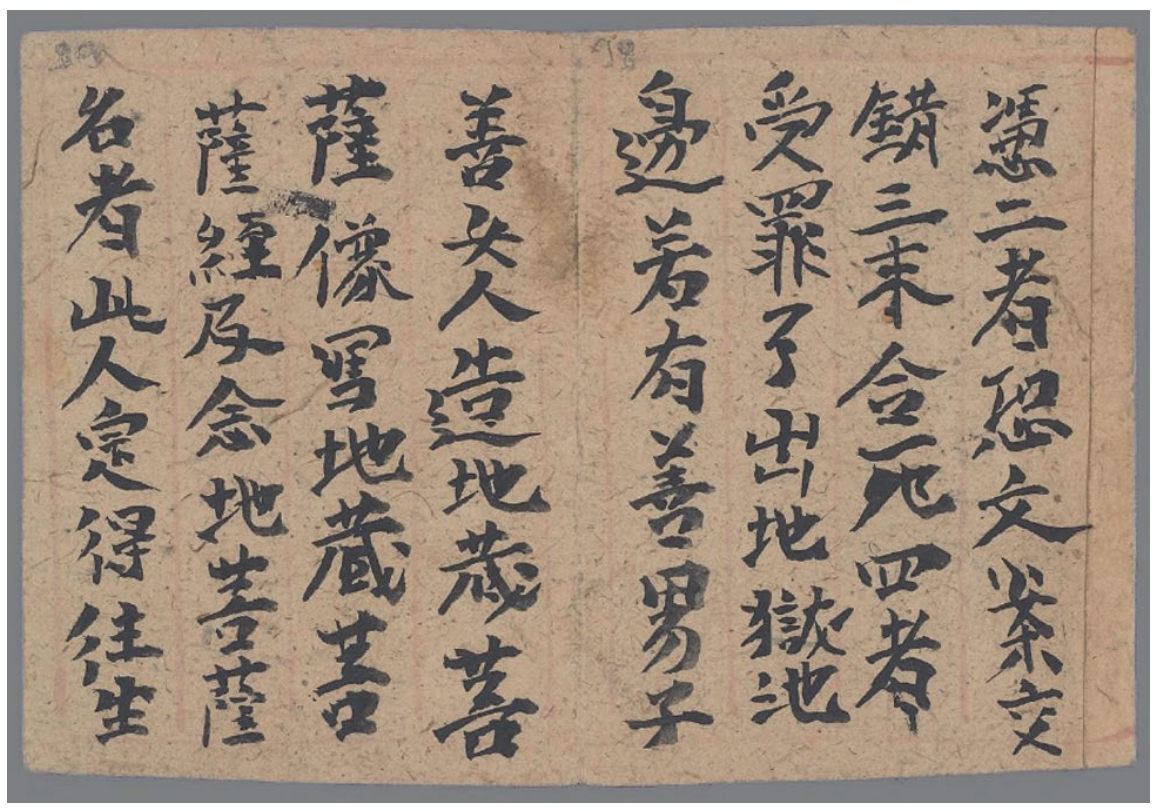

Fig. 23c: Hand C in manuscript P.3760.

The distribution of the three hands in the manuscript is markedly uneven. Using the folded pages of the concertina as a unit of measure, the amount of text each of them takes up from the total of 113 inscribed pages is as follows: ${ }^{163}$

\begin{tabular}{lll}
\hline Hand A: pp. $2-48$ & 46 pages & $40.7 \%$ \\
Hand B: pp. $49-97$ & 49 pages & $43.4 \%$ \\
Hand C: pp. $97-100$ & 2.5 pages & $2.2 \%$ \\
Hand B: pp. $100-115$ & 15.5 pages & $13.7 \%$ \\
\hline
\end{tabular}

The places where the hands change have no correlation with the textual or codicological boundaries in the manuscript. Although they sometimes change in mid-sentence, this usually happens at the beginning of a new line, which is easy to achieve because the lines are very short, only 6-7 characters each. Another intriguing phenomenon is that hands A and B initially copied about the same amount of text (i.e. 46 and 49 pages), stopping 18 pages before the end. At

163 The page numbers used here are those written on the pages by modern conservators. 
that point hand $C$ stepped in but copied only 3 pages, leaving $B$ to finish the remaining portion. It is conceivable that this had been the plan all along, but it may well have been so that hand $\mathrm{C}$ was having difficulties and hand $\mathrm{B}$ had to help out. Indeed, as far as it is possible to judge from the handwriting, hand $\mathrm{C}$ may have suffered from a neurological disorder that affected his or her writing. ${ }^{164}$ This would also explain why the last portion of text, even without the help from hand B, was shorter than those of the two other hands (18 vs. 46/49 pages). A disorder of this sort suggests that the individual was older. The scenario emerges of three individuals, perhaps family members, dividing the total amount of text they wanted to copy into two larger and one smaller portion, anticipating that copying would be difficult for hand C. Finally, hand $\mathrm{C}$ was unable to finish even the reduced portion allocated to him or her and had to rely on hand $\mathrm{B}$ to finish the task.

This does not mean, however, that the other two hands were professionals. The pages they wrote, which make up the bulk of the manuscript, include a number of idiosyncratic character forms, as well as glaring omissions from the text of the scriptures. Among these is hand B's writing the duplicate characters of the word zhongzhong 種種 ('various') with reversed forms as 重乐種, in which the first graph is an unattested orthographic form. Another example, also by hand B, is the phrase shouzu 手足 ('hands and feet'), written as with the first character mimicking the structure of the second one. Once again, the result is an unattested orthography that is simply a mistake. Hand A makes its own share of mistakes, repeatedly omitting characters from the name of Bodhisattva Guanyin 觀音菩薩, writing it as Guanshiyin pu 觀世音菩 or Yin pusa 音 菩薩. These mistakes attest to the rudimentary writing skills of the hands in this manuscript, which makes it unlikely that either of them was a hired hand. A more likely scenario is that all three persons were of the same family.

Looking at the manuscript in terms of content, it contains three different texts from among those commonly occurring in multiple-text manuscripts. It is, therefore, not surprising to see them together here in yet another concertina. As was the case in other examples, the Guanyin jing is the first of the three texts, which are as follows:

164 A well-known case of tremor in medieval England are manuscripts written by the so-called 'tremulous hand of Worcester'; see Franzen 1991. For an attempt to diagnose the type of tremor in these manuscripts, see Thorpe and Alty 2015. 
1. Miaofa lianhua jing Guanshiyin pusa Pumen pin di nianwu 妙法蓮華經觀世音 菩薩普門品第廿五

2. Foshuo Dizang pusa jing 佛說地藏菩薩經

3. Foshuo xuming jing 佛說續命經

The first text is the longest, taking up 91 of the 113 inscribed pages. Reaching the end of the first side, it continues seamlessly onto the other. Texts Nos. 2 and 3 take up only 22 pages in total. In the end, text No. 3 finishes on the very last page, managing neither to run out of space nor to leave any blank pages. This was by no means a fortunate accident, for the concertina form makes it impossible to add or remove pages. Evidently, the person who created the physical manuscript knew in advance the total number of pages required for the three texts and made sure that all three hands copied them according to the plan. Most likely, they copied the scriptures from another concertina in which the same three texts followed each other in the same order.

The manuscripts examined in this section contained at least two of the four texts present in manuscript S.5618 (listed in Table 3). We have identified a total of seven such items (including S.5618), all of which were either codices or concertinas with at least three different texts. Considering some of these texts were not very common, the pattern is remarkable. At the same time, it is important to note that not all codices belong to this group of multiple-text manuscripts, for many of them contain primers or simple writing exercises, model letters or just one Buddhist text (i.e. Diamond sutra). The same holds true for concertina manuscripts, which may include other types of texts. ${ }^{165}$ Therefore, the examples discussed in this chapter represent only a subset of Chinese codices and concertinas from Dunhuang.

In a multilingual society, such as Dunhuang in the ninth and tenth centuries, the social and ritual practices behind the production of such multiple-text booklets were certainly not limited to Chinese manuscripts. Focusing on a group of Tibetan manuscripts that contain Avalokiteśvara (i.e. Guanyin) texts, van Schaik notes that although the pothi was the most common form for Tibetan manuscripts from Dunhuang, followed by the scroll, a large proportion of the Avalokiteśvara texts were written on concertinas and codices. One of the features of these manuscripts was that many of them were collections of several

165 Just to name two examples, S.5693 is a gazetteer and S.5765 is a fragment of the Fozang jing 佛藏經 $(\mathrm{T} 653,15)$ translated by Kumārajīva. 
short prayers and sādhanas. ${ }^{166}$ They were usually of small size to facilitate portability on the body. On the function of such manuscripts, van Schaik writes:

These collections of prayers and sādhanas may have been used by wandering monks or lay yogins either for personal use or when providing religious services for others. In postimperial Tibet, such figures, who would have been literate in Buddhism but without monastic sponsorship, would probably have been common. It is easy to imagine most of the Avalokiteśvara texts in the Dunhuang collections being used in this way-texts to be read to the dying or deceased, rituals for healing the sick, helping crops, and sorting out personal problems, as well as general-purpose, all-accomplishing prayers like the 108-epithet prayer in praise of Avalokiteśvara. ${ }^{167}$

This, of course, resonates with what the function of Chinese multiple-text manuscripts may have been. This group of Tibetan codices and manuscripts come from the Guiyijun period, just like their Chinese counterparts. ${ }^{168}$ They exhibit obvious similarities with the physical characteristics of the Chinese manuscripts, including their size, colour and type of paper. For example, manuscript Pelliot tibétain 37 (Fig. 24) is a glued codex with a collection of texts on the after-death state. It consists of 28 bifolia but is, in its current form, incomplete. The leaves have trimmed corners and a slanting top edge. The booklet is $13.7 \times 15 \mathrm{~cm}$ in size, thus, when closed, almost square in shape. The size is significant because it indicates that the bifolia were probably cut from sheets of paper $27.4 \mathrm{~cm}$ and 45 $\mathrm{cm}$ wide, very similar to the size of sheets used for Chinese scrolls.

166 van Schaik 2006, 62-64. The sādhanas are the visualisation and recitation practice of the deity (ibid., 58).

167 Ibid., 63.

168 Several items from this group can be dated to the second half of the tenth century; ibid., 64. 


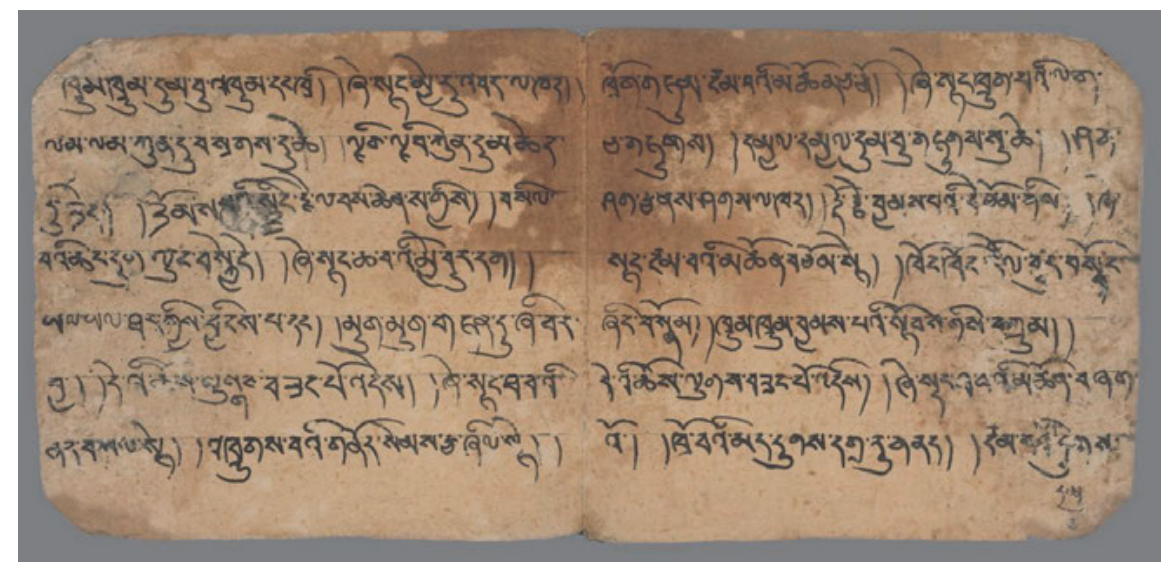

Fig. 24: Two opposing pages from the Tibetan codex Pelliot tibétain $37 .(13.5 \times 15 \mathrm{~cm}$; Bibliothèque nationale de France)

Accordingly, there is a series of similarities between these groups of Chinese and Tibetan manuscripts, including their time frame, book form, shape, size, and even the fact that they contain multiple texts related to ritual services. Whether they actually belong to the same group of manuscripts as the Chinese multiple-text manuscripts discussed in this chapter requires a comparative analysis of the texts contained in them.

\subsection{Scrolls}

Looking at the phenomenon in the light of the physical form of manuscripts, it is apparent that the texts found in such multiple-text items also appear in manuscripts that are not codices or concertinas. The previous section described seven manuscripts with the Foshuo xuming jing (line 2 of Table 3) and at least one other text, and all proved to be multiple-text codices or concertinas. Of the remaining 11 items with the Foshuo xuming jing (but none of the other texts in Table 3) only Дx-1009 and S.5581 are codices, while the other items are scrolls, fragments of scrolls, or stand-alone sheets of paper. Some of these manuscripts feature a very similar array of texts. For example, BD00693, a scroll $184 \mathrm{~cm}$ in length, contains the following eight texts: 
1. Foshuo xuming jing 佛說續命經

2. Foshuo jie baisheng yuanjia tuoluoni jing 佛說解百生怨家陀羅尼經

3. Foshuo yan shouming jing 佛說延壽命經

4. Foshuo tianqingwen jing 佛說天請問經

5. Bore boluomiduo xin jing 般若波羅蜜多心經

6. Zaota gongde jing 造塔功德經 (Sutra on the Merit of Building a Stūpa)

7. Foshuo dasheng sifa jing 佛說大乘四法經 (Sutra Spoken by the Buddha on the Four Dharmas)

8. Foshuo shixiang jing 佛說十想經 (Sutra Spoken by the Buddha on the Ten Contemplations)

The overlap with the content of the group of manuscripts described in this chapter is clear. The first five texts match those seen in manuscripts S.5531 and P.3932, attesting to the similarities with the structure of multiple-text codices. Yet the remaining three texts are different from those commonly seen in codices and concertinas. The Zaota gongde jing (Sutra on the Merit of Building a Stūpa) and Foshuo dasheng sifa jing (Sutra Spoken by the Buddha on the Four Dharmas) are both translations by Divākara 地婆訶羅 (613-688). ${ }^{169}$ The Foshuo dasheng sifa jing and Foshuo shixiang jing (Sutra Spoken by the Buddha on the Ten Contemplations) also occur in manuscript P.3919, which is a pothi with a series of texts that are, once again, different from those in multiple-text codices and concertinas. ${ }^{170}$ This shows that despite textual similarities, there are also important differences that set this scroll apart from the codices and concertinas. Aside from the obvious disparity between the two book forms, the texts in the scroll are written in the same hand. Further to which, this hand is visibly more competent than many of the hands we have seen in the codices and concertinas. There are insertions and some crude corrections, such as blotting out mistaken words with ink and writing corrections on the side, yet the handwriting on the whole is uniform and competent. This seems to indicate a different background from multiple-text codices and concertinas written in different hands, frequently with very basic writing skills.

169 Atypically, the head title of the scripture (i.e. Zaota gongde jing 造塔功德經) in this manuscript is shorter than the end title (Foshuo zaota gongde jing 佛說造塔功德經). A complete translation of the Zaota gongde jing is available in Boucher 1991, 8-10; see also Miller 2018. On Divākara's activities, see Forte 1974 and 2015, 50-52; Chen 2007, 217-223.

170 In fact, the Foshuo shixiang jing only occurs in four Dunhuang manuscripts, i.e. BD00693, P.3919, Hane-287 and ZSD2207. 
One of the other items with the Foshuo xuming jing is S.5679, a $122 \mathrm{~cm}$ long scroll containing three scriptures. The verso has a few scribbled characters, such as foshuo 佛說 ('spoken by the Buddha') and the name of the Longxing monastery 龍興寺, none of which amount to an actual text. ${ }^{171}$ The three successive texts in this scroll are as follows:

1. Foshuo yan shouming jing 佛說延壽命經

2. Foshuo xuming jing 佛說續命經

3. Jiu zhu zhongsheng kunan jing 救諸眾生苦難經 (Sutra on Relieving Sentient Beings from Hardship)

This item is similar to BD00693 as it is a scroll featuring a selection of similar texts, but only three of them. Furthermore, the third text is written in a different hand, a detail that makes the manuscript more semblant to multiple-text codices and concertinas. Another scroll similar to it both in terms of its physical form and content is P.2374 $(111 \mathrm{~cm})$. The first two texts in it match those in S.5679 (i.e. Foshuo yan shouming jing and Foshuo xuming jing) but the third one is the Foshuo tianqingwen jing 佛說天請問經. The entire manuscript is written in the same confident hand, including the colophon at the end. There are some corrections and insertions and the end title of the last text is erroneously given as Foshuo yan shouming jing, rather than the correct Foshuo tianqingwen jing. ${ }^{172}$ Fortunately, there is a colophon which states the time of copying as the eighth day of the fourth month of 959. It further explains that the dhyāna master Huiguang 惠光 of the Chengdian Chan Monastery 承典禪院 in Guazhou 瓜州 copied the three texts (i.e. Yan shouming jing, Xuming jing and Tianqingwen jing) in a total of forty-nine scrolls on behalf of a donor. In other words, the three scriptures together formed a set and Huiguang made forty-nine copies, all in scroll form. Presumably, manuscript P.2374 is one of those forty-nine copies. Thus, the ultimate purpose of producing the manuscripts was to generate merit for someone else. The number forty-nine undoubtedly refers to the 'seven-seven feast' 七七齋 associated with the forty-nine days of mourning the dead. As a consequence, the scroll was what Kuo Liying calls an 'offering sutra', copied in multiple copies for the sake of dedicating blessings to the deceased. ${ }^{173}$

171 Another manuscript with a similar disconnected reference to the Longxing monastery is the Sino-Tibetan scroll IOL Tib J 754; see van Schaik and Galambos 2012.

172 Li Xiaorong 2013, 194 suggests that Huiguang used the title Foshuo yan shouming jing as a joint title for the three scriptures, as they all have content related to extending life. I think he simply made a mistake.

173 Kuo 2000, 692-694. 
Perhaps the most well-known example of such a manuscript is P.2055, the final colophon of which lists the sutras copied by Zhai Fengda 翟奉達 (d. 966) for the benefit of his deceased wife during the seven feasts commemorating each seven-day period, as well as those on the hundredth-day, one-year and three-year anniversaries. The texts include the Tianqingwen jing and the Yanluo jing 閻羅經 (i.e. Foshuo Yanluo wang jing), however, most of them are scriptures that do not occur in concertinas and codices. ${ }^{174}$ The scroll itself only contains the last three scriptures, each with a separate colophon ascribing it to a particular day within the schedule of feasts laid out in the long colophon at the end of the scroll. The other scriptures from this set survive in two other scrolls (BD04544 in the National Library of China and TY193 in the Tianjin Arts Museum), each with multiple scriptures.

In terms of its physical structure, P.2055 is a composite scroll assembled from several smaller pieces, some of which are darker in colour than others. Significantly, there is a clear seamline at the end of each of the three scriptures (and their colophons), showing that they were not copied on the same scroll from the start but were glued together subsequently. Their order reveals that each newer scripture was glued before (i.e. to the right) of the previous one, so in its final form the scroll essentially begins with the text copied last. The long colophon at the end of the whole scroll yet again constitutes a separate sheet of paper. ${ }^{175}$ The manuscript, therefore, grew over the course of several months and reached its final form only after the completion of the entire set of rituals. This process is clearly different from the usual way of gluing sheets of paper together into a scroll before writing on it. The scroll with three scriptures we see today encapsulates a prolonged process of ritual mourning and dedicating merits to a deceased relative.

Zhai Fengda was most likely the individual who wrote the colophons but researchers have suggested that the scriptures themselves were in another

174 For a translation of Zhai's colophon with the list of the sutras, see Mollier 2008, 69; on the 'seven-seven feast', see Makita 1976, 338-340, Teiser 1994, 102-121 and Du Doucheng 2004. A similar memorial service called shichi shichi no ki 七七/忌 was also known in Hei'an 平安 (794-1185) Japan; see Tanabe 1984, 394-395.

175 Unfortunately, I have access to BD04544 and TY193 only through facsimile reproductions which are insufficient for a reliable examination of physical structure. As far as I can see, there are no seamlines following the end of individual scriptures, which suggests these two scrolls may not be composite manuscripts. Of course, one can ascertain this only by examining the original items, thus I limit my observations here to P.2055. 
hand. ${ }^{176}$ The differences, however, are largely in the width of individual strokes, while in terms of their orthographic structure and general balance the characters in the colophons and the main texts do not exhibit conclusive differences. Due to this, I think that Zhai Fengda also copied the scriptures, but using a sutra-copying hand. As was customary in the region during the Guiyijun period, he used a pen instead of a brush, which is perceptible in the even thickness of strokes in the colophons. ${ }^{177}$ But when copying the scriptures, he made an effort to emulate the strokes of brush-written characters, which makes the hand look different. Essentially, he copied the scriptures in a formal hand, in contrast with his everyday handwriting evidenced in the colophons. He was, of course, a highly educated individual able to copy larger quantities of texts and thus his situation may have been unusual.

The similarities in form and content between scrolls such as P.2374, BD00693 and P.2055 suggest that they all stem from a similar social context, which largely revolved around mourning practices and assigning merits to the dead. This background fits well with both the types of texts and the colophons, some of which expressly make references to the process of commemoration. As a group, these scrolls have important differences from multiple-text codices and concertinas. One clear difference is that the scrolls maintain the traditional Chinese book form that had been in continuous use from the early medieval period. By contrast, the portability of codices and concertinas must have played a key role in their function. Secondly, for the most part, the scrolls are written in the same hand, as opposed to the booklets which typically evidence the involvement of several hands. Trivial as it may seem, this is a major difference because it attests to an entirely different process of production which, in turn, points to a dissimilar liturgical practice. Thirdly, the scrolls are much more likely to include colophons which state the purpose and context of copying. In contrast, the codices and concertinas usually have no colophons, and when they do, their wording is more generic and does not allow us to establish a direct link between the manuscripts and mourning practices.

176 The difference between the hands in the scriptures and colophons was noted in Gernet and $\mathrm{Wu} 1970,40$. Teiser 1994, 102-103 is also of the opinion that the three scriptures were probably written by a different hand from the individual who wrote the dedications.

177 Fujieda 1973, 438 and Fujieda 1968. 


\subsection{Conclusions}

This chapter looked at Chinese codices and concertinas from Guiyijun Dunhuang as examples of multiple-text manuscripts. Such manuscripts consist of a series of Buddhist texts copied successively into a single booklet which probably served apotropaic and ritual purposes. The manuscripts are of similar size and physical form and contain a combination of texts from a limited pool of scriptures and mantras. The small size and trimmed corners imply that individuals may have carried the booklets on their body. The textual and physical parallels confirm a connection between them, making it likely that they were produced not only under similar circumstances but also within a restricted time range. The discrepancies between the individual examples, however, reveal that there was a certain degree of arbitrariness as to which texts and in what order were copied into such manuscripts.

Most multiple-text manuscripts examined in this chapter were written in more than one hand, evidencing the participation of several persons. The examples suggest that in some cases family members produced a booklet on their own, yet in other cases they may have paid someone to bind the book properly and copy a portion of the texts. Paying for the production of the physical manuscript would have been part of the act of offering that earned the donors karmic merit. Donors took possession of these merits and activated the religious power of the manuscript by copying a portion of the text in person. The multiple-text booklets seem to be unique in that they involved each family member personally in the process of producing the manuscript. While each individual could have easily completed an entire manuscript on their own (and probably most of them did on other occasions), it was vital they all participated in the production of the same object. Family members who had obvious difficulties writing yet copied a few pages demonstrated that personal involvement of all participants was essential for the booklet to function properly.

It is significant that in some cases the last pages of multiple-text codices or concertinas remain blank, as this phenomenon may offer a glimpse into the process of production. It tells us that the manuscripts with the series of scriptures in them took shape over a longer stretch of time, rather than within a day or two. Such manuscripts may have continued to grow throughout their use. Their owners were in no hurry to finish them but kept them available for new 'contributions'. Whatever the case may be, the blank pages, which have often been ruled, should not be seen as a miscalculation on the part of the individuals who produced the manuscript. They did not constitute leftover space but were perhaps the most important part of the manuscript, inviting members of a family to continue appropriating the karmic merits generated by the act of copying. 